\title{
WIND SYSTEM DOCUMENTATION (U)
}

\author{
by J.R. Froggatt
}

Westinghouse Savannah River Company

Savannah River Site

Aiken, South Carolina 29808

Other Authors:

C. P. Tatum

(WSRC)

This paper was prepared in connection with work done under Contract No. DE-AC09-89SR18035 with the U. S. Department of Energy. By acceptance of this paper, the publisher and/or recipient acknowledges the U. S. Government's right to retain a nonexclusive, royalty-free license in and to any copyright covering this paper, along with the rigtit to reproduce and to authorize others to reproduce all or part of the copyrighted paper. 


\section{DISCLAIMER}

This report was prepared as an account of work sponsored by an agency of the United States Government. Neither the United States Government nor any agency thereof, nor any of their employees, makes any warranty, express or implied, or assumes any legal liability or responsibility for the accuracy, completeness, or usefulness of any information, apparatus, product, or process disclosed, or represents that its use would not infringe privately owned rights. Reference herein to any specific commercial product, process, or service by trade name, trademark, manufacturer, or otherwise does not necessarily constitute or imply its endorsement, recommendation, or favoring by the United States Government or any agency thereof. The views and opinions of authors expressed herein do not necessarily state or reflect those of the United States Government or any agency thereof.

This report has been reproduced directly from the best available copy.

Available to DOE and DOE contractors from the Office of Scientific and Technical Information, P.O. Box 62, Oak Ridge, TN 37831; prices available from (615) 576-8401, FTS 626-8401.

Available to the public from the National Technical Information Service, U.S. Department of Commerce, 5285 Port Royal Rd., Springfield, VA 22161.

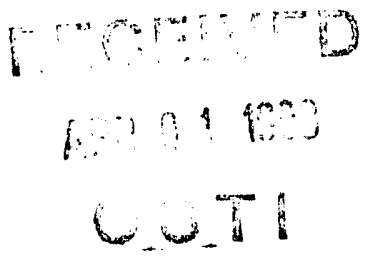




\title{
WIND
}

\section{SYSTEM}

\section{DOCUMENTATION (U)}

\author{
Authors: J.R. Froggatt \\ C.P. Tatum
}

Date: 15 January 1993 
CHAP TER 1

** DATA COLLECTION PROGRAMS **

1.1 ARCIV1 (Collect Data Every $11 / 2$ Sec. And Summarize Every 15 Minutes)

\section{IDENTIEICATION :}

Archiving system TV and SR Tower data collection program

NAME: ARCIVI

TYPE: WIND system data collection program

FUNCTION :

This program executes on both WIND1:: and WIND2::. On WIND2:: it runs in a primary data collection mode and asserts this by obtaining an exclusive lock on resource ARCIV1. On WIND1: : the program attempts to obtain an exclusive lock on resource ARCIV1. If successful (only possible when WIND2:: version is not operating) program executes but checks to see if the WIND2:: version is requesting the lock after every data gathering pass (about every 1.5 seconds). Any time the WIND2:: version requests the lock it is granted and data collection ceases on WIND1: : .

When operating in data collection mode, this program reads TV tower, Central Climatology (CL) tower, and the SRP area tower data and accumulates it in global commons ARCOM and ARCOM CL. New data readings are collected every 1.5 seconds, converEed to engineering units, azimuth corrected for winds fluctuating between 0 and 360 degrees, and accumulated for the curxent 15 minute interval.

At the end of the 15 minute period, maximum values, mean values, and standard deviations are computed for wind speeds, azimuths, elevations and temperatures for the TV, SRP, and CL towers.

Also, the CL tower measures a number of additional meterological values. $U$ and $V$ vector components are also accrued during the 15 minute period. This allows the option of later retrieving either vector or scalar derived wind speeds and azimuths. After the above values have been calculated at the end of the 15 minute period, process ARCIV2 is invoked to quality assure the data and write it to disk. Both versions of ARCIV2 (WIND1:: and WIND2::) write data to the same files (located in WD: on SHADOW1:). ARCIV2 is only activated on the system with possession of the exclusive lock on ARCIV1. 


\section{INITIATION :}

Program is requested for execution in the startup iile. Also, program is stopped and restarted manually when a calibration coefficient has been changed by program NEWEIL, NEWEL8, or NEWEI, CL. This is done to allow the new coefficients to be read Into global common ARCOM and ARCOM_CL as the program begins execution.

REAI TTME CONSIDERATIONS :

Once program has been initiated, it runs continuously. at a high priority.

AUTHOR: J.R. Froggatt, Process Systems Group, ESD, E. I. DuPont DATE: $11 / 4 / 85$ LAST REVISED: $9 / 15 / 88$

1.2 ARCINI (ARCIV1 SUBR - Program Startup Initialization)

\section{IDENTIF ICATION :}

ARCIVI STARTUP INITIALIZATION SUBROUTINE

NAME: ARCINI

TYPE: ARCIV1 SUBROUTINE

\section{FUNCTION :}

This subroutine first determines which system (WIND1: : or WIND2::) that the program is operating on. This will allow the Archiving programs to operate properly depending upon whether the other system is in operation or not. The subroutine then initiates the execution of the individual subprocesses that will read from the individual Micromac units and place the data into auxiliary Common ARCOM1. In addition, the subroutine reads and enters into Common ARCOM the coefficients to be used in calculating engineering units from raw voltages. The TV data is read from WD:ARCOBE.DAT and the SR tower data is read from WD:SRCOEF.DAT. The subroutine also reads the quality control flags written during the last execution OF ARCIV2 from WD:ARCQTY.DAT and places them into ARCOM.

CALIING SEQUENCE: Called by ARCIV1 one time when program begins execution.

AUTHOR: J.R. Froggatt, Process Systems Group, ESD, E.I. DuPont

DATE : $8 / 10 / 83$

LAST REVISED: $07 / 08 / 88$ 
1.3 ARCIBE (ARCIV1 SUBR - Initialization Prior To New 15 Min Data Collection)

IDENTIF ICATION :

Subroutine to init common ARCOM, ARCOM_TR, and ARCOM_CL an prior to $15 \mathrm{~min}$ data accrual

NAME: ARCIBF

TYPE: ARCIV1 subroutine

FUNCTION :

This subroutine initializes the portions of global commons ARCOM, ARCOM TP, and ARCOM CL used for the accumulation of current 15 minute data. AlI variables initialized are zeroed out with the exception of those used to store 15 minute maximum values. These variables are initialized with artificially low values. All variables handled are contained in global commons ARCOM, ARCOM_TP, ARCOM_CL.

CALLING SEQUENCE :

Subroutine called by ARCIVl every 15 minutes prior to storing new data for the 15 minute period just begun.

AUTHOR: J.R. Froggatt, on Line Systems Group, ESD, E.I. DuPont DATE: $11 / 4 / 85$

LAST MODIFIED: $9 / 9 / 88$

1.4 ARCNB (ARCIV1 SUBR - Acquire New Data From The Various Met Towers)

IDENT IF ICAT ION :

Subroutine to read new bursts of TV, Climatology, and Area Tower data. NAME : ARCNB

TYPE: ARCIV1 Subroutine

EUNCTION : 
This subroutine reads new bursts of data from the $T V, C L$, $A, C, D, F, H, K, L$, and $P$ towers. All data in received from Micro Mac units located at tise cifferereni tüwes. Data is in the Esm of $\lambda S C I I$ characters representing voltage signais received from the various meterological instruments. Data is received and processed by ARCIVI every 1.5 seconds.

CALIING SEQUENCE: Called by ARCIVI each time pgm ready for data. REAL TIME CONSIDERATIONS :

Data from the various towers must be received before a 1.49 second timeout or it is ignored for the current pass. The 1.49 second timeout is the time allowed for gathering data since the VAX 8550 requires about 0.01 seconds to process the data each pass and data is required every 1.5 seconds.

AUTHOR: J.R. Froggatt, Process Systems Group, ESD, E.I. DuPont

DATE: $7 / 31 / 80$

REVISED: $01 / 10 / 89$

\subsection{ARCENU (ARCIV1 SUBR - Calculation of Engineering Units)}

\section{IDENTIFICATION :}

Subroutine to convert TV, SR(includes TP), and CL tower voltages to eng units

NAME: ARCENU

TYPE: ARCIVI subroutine

FUNCTION :

This subroutine converts from raw voltages to engineering units. The equations use emperical coefficients developed while calibrating the field instruments. Any measurement for which the voltage is out of range and any engineering unit value which is obviously incorrect is flagged as an error and is not used any further.

CALLING SEQUENCE :

Called by ARCIVI after obtaining raw voltages from subroutine ARCNB.

INITIALIZATION :

The calibration coefficients used by the equations in this subroutine are contained in files WD:ARCOEF.DAT, WD:SEVCOE.DAT, WD:COEE_TP, and WD:COEF_CL.DAT for the TV, 
SR (plus TP), AND CL towers respectivly. These coefficients are read into global commons ARCOM ARCOM_TP, and ARCOM_CL by subroutine firciñ wieñ AnCIVI begins executicn. If eny of these files is modified, it is necessessary to abort and reactivate ARCIV1 to place the revised data into ARCOM, ARCOM_TP, and ARCOM_CL.

AUTHOR: R.A. Mueller ENVIRONMENTAL TRANSPORT DIVISION J.R. Froggatt, Process Systems Group, ESD, E.I. DuPont

DATE : $9 / 26 / 80$

REVISED : $11 / 06 / 85$

REVISED : $10 / 20 / 85$

REVISED: $1 / 22 / 88$

1.6 ARCAZC (ARCIV1 SUBR - Kern/Pendergast Azimuth Correction)

IDENT IF ICATION :

Kern/Pendergast Azimuth correction algorithm subroutine

NAME : ARCAZC

TYPE: ARCIV1 SUBROUTINE

FUNCTION :

This subroutine is designed to eliminate the problem encountered when wind directions fluctuate between values near 0 degrees and values near 360 degrees. The basic strategy involves maintaining an average value for each measured azimuth for the current 15 minute interval and comparing it with the currrent reading. Prior to any comparisons, values are biased upward by 720 degrees to avoid any problems that would result from negative numbers. Negative numbers are a possibility even though azimuth values supplied to this subroutine are between 0 - 360 degrees because the algorithm used sometimes subtracts 360 degrees from the original reading.

Three comparisons are made involving the current 15 minute average and the current reading. They are:

1) Average vs Current

2) Average vs (Current +360 )

3) Average vs (Current - 360)

If 1) results in the smallest difference no further adjustment is made beyond the original biasing of 720 . 
If 2) results in the smallest difference, 360 is added to the original value and if 3 ) results in the smailest difiesiñe, $3 \in 0$ is subtranted from the original value. inese vaiues are subsequently accumulated in sum $x$ and sum $x * \star 2$ values by subroutine ARCADD. The mean and standard deviation are later calculated by subroutine ARCUPD at the end of the 15 minute period and the bias of 720 is backed out from the mean value.

The algorithm basically holds fluctuations between 0 and 360 degrees to the vicinity of either 0 (720) or 360 (1080) depending upon where the average happens to be. This eliminates the problem of distorted mean values and standard deviations.

Mean values are also computed using $U$ and $V$ vector components and these values are most often used by WIND system data retrieval programs. However, the standard deviations computed using the sum $x$ and sum $x * \star 2$ values resulting from this subroutine are the ones used by the data retrieval programs.

CALIING SEQUENCE:

Called by ARCIV1 after ARCIVI calls ARCENU

INITIALIZATION :

At beginning of a new 15 minute period, new average azimuth values are begun.

AUTHOR: T.R. Froggatt, Process Systems Group, ESD, E.I. DuPont

DATE : $8 / 1 / 80$

REVISED : $11 / 06 / 85$

REVISED : $1 / 22 / 88$

1.7 ARCADD (ARCIV1 SUBR - Update Of Running Totals With Latest Readings)

IDENT IE ICATION :

Subroutine to add latest values to accumulating $15 \mathrm{~min}$ values

NAME : ARCADD

TYPE : ARCIV1 SUBROUTINE

FUNCTION :

This subroutine adds the latest TV, SR, and CL tower data into accumulating variables located in global commons ARCOM, ARCOM_TR, 
and ARCOM TR. The number of good readings is incremented (if appropriate), and the value is added to sum $x$ and the square of the value is added to sum $x * \alpha 2$ for eacil good redijiy. In additiva, the current maximum for each variable is collected by comparing current values with previous maximums.

This subroutine also accrues totals for $U$ and $V$ vector components. This allows a more accurate determination of wind speeds and azimuths. However, the scalar values for speed and direction are also maintained.

the formulas used are:

$$
\begin{aligned}
& U=-(\text { SPEED } \star \operatorname{COS}(\text { AZM) }) \\
& V=-(\text { SPEED } \star \operatorname{SIN}(\text { AZM }))
\end{aligned}
$$

CALIING SEQUENCE: Called by ARCIV1 after ARCAZC.

INITIALIZATION :

Accumulating variables in global commons ARCOM and ARCOM CL are zeroed out at beginning of 15 minute period by subroutine ARCIBE .

AUTHOR: J.R. Froggatt, Process Systems group, ESD, E.I. DuPont

DATE : $9 / 26 / 80$

REVISED : $11 / 06 / 85$

REVISED : $10 / 20 / 87$

REVISED : $1 / 22 / 88$

\subsection{ARCUBE (ARCIV1 SUBR - End of 15 Minute Data Collection Period Processing)}

\section{IDENTIEICATION :}

Subroutine to update $15 \mathrm{~min}$ buffer prior to writing to disk

NAME: ARCUBF

TYPE: ARCIVI subroutine

FUNCTION :

This subroutine transfers data collected during the 15 minute period just ended to a holding area. Means and standard deviations are computed from the SUM $X$ and SUM $X \star \star 2$ values accumulated during the period. In addition, some preliminary quality assurance is performed on the mean values computed and the appropriate quality assurance flags are set.

CALLING SEQUENCE: Called by ARCIV1 at end of 15 minute period REAL TIME CONSIDERATIONS : 
Runs just prior to ARCIVI request for execution of program ARCIV2

AUTHOR: J.R. Froggatt, Process Systems Group, ESD, E.I. DuPont DATE : $11 / 4 / 85$

1.9 TMPPUT (ARCIV1 SUBR - Place Latest 15 Minute Data On Disk)

\section{IDENTIF ICATION :}

Subroutine to update $15 \mathrm{~min}$ buffer prior to writing to disk

NAME : ARCUBE

TYPE: ARCIVI subroutine

FUNCTION :

This subroutine transfers data collected during the 15 minute period just ended to a holding area. Means and standard deviations are computed from the SUM $x$ and SUM $x * \star 2$ values accumulated during the period. In addition, some preliminary quality assurance is performed on the mean values computed and the appropriate quality assurance flags are set.

CALLING SEQUENCE: Called by ARCIV1 at end of 15 minute period REAL TIME CONSIDERATIONS :

Runs just prior to ARCIV1 request for execution of program ARCIV2

AUTHOR: J.R. Froggatt, Process Systems Group, ESD, E.I. DuPont DATE : $11 / 4 / 85$

1.10 ARCRD (ARCIVI SUB PROCESS PGM - Read Met Twr UMAC Data)

IDENT IF ICATION :

Pgm to read data from a specific met twr depending upon subprocess name NAME : ARCRD

TYPE: ARCIV1 Subprocess 
FUNCTION :

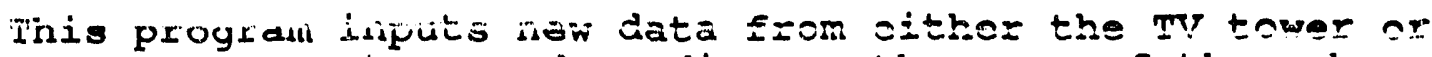
one of the SR towers depending on the hame of the subprocess the program is running under. Currently, the TV tower, $C L$ tower and $A, C, D, E, H, K, L$, and $P$ Area towers have individual Micro-Mac units supplying data. The program is signaled from detached process ARCIVI when data is desired using an event flag. This program signals ARCIVI that data is ready also thru the use of an event flag.

CAILING SEQUENCE: Signaled by detached process ARCIV1 each time it requires new data.

REAL TIME CONSIDERATIONS :

While this routine is waiting for $I / O$, other pgms in the system can execute. ARCIV1 continuously loops around processing the latest raw data supplied by this program in it's current subprocess as well as other copies of this program executing in subprocesses devoted to other Area towers.

AUTHOR: J.R. Froggatt, on Line systems Group, ESD, E.I. DuPont DATE: $11 / 85$

LAST MODIFIED : $10 / 87$

1.11 ARCIV2 (Quality Assure 15 Minute Average Data And Write To Disk)

IDENTIF ICATION :

Quality Assurance Program

NAME : ARCIV2

INSTALLED NAMES: ARCIV2

TYPE: WIND System Data Collection Program

FUNCTION :

This program is called at the end of every 15 minute period by data collection program ARCIV1. The program's purpose is to QUALITY Assure the data and then write it to disk using subroutine ARCPUT. Erroneous data is replaced with appropriate estimates. The Quality Assurance Algorithm implemented in the WIND System operates in two phases. The first phase consists of three schemes for determining invalid data, while the second phase is concerned with replacing the invalid data with estimated values. 
Data is flagged as being invalid if an jnstrument is known to be out of service (done manually using pgm flags). In additicon, ix iess lian iof of the expectad number of readings for a 15 minute period fox a particular instrument are within the known ranges of the instrumentation, the data for that period and instrument is flagged (performed by ARCIV1 subroutine ARCUBF). The data that pass this initial screening is further checked against the average of all similar data items (e.g., all SRS Tower Azimuths). Any observation that differs by more than a specific amount from the mean is flagged, and a new mean is calculated from the remaining points. This procedure continues until an acceptable mean is computed that involves at least two instruments, or all of the observations are flagged.

The allowed deviation from the mean is a specified number of estimated standard deviations of the variable in question. The estimated standard deviations are calculated with empirical relationships based on meteorological conditions and statistievi paramters, such as Atmosperic stability and Sampling Period.

An additional consideration is required in Quality Controlling the data collected on the WJBE-TV Tower. Here the individual data points are compared to the mean values of like data items at different tower heights. In order to make meaningful comparisons, all data are adjusted to a common reference height. Speed, Siga, and sige are adjusted using a power law relationship while Temperature and Wind Direction are adjusted using a linear relationship. In all cases, equation parameters are used that have been empirically developed as a function of Atmospheric stability.

The second phase of the Quality Assurance Algorithm involves replacement of bad lata with estimated values. For the SRS Towers, this merely consists of substituting the mean of the accepted values for the rejected data. If all values of a particular type have been rejected, the last available Average SRS Tower is used. However, if this is more than two hours old, adjusted data from Bush Field in nearby Augusta, Georgia are used. If Bush Field data is more than two hours old, no Quality Assurance is performed and a message to that effect is displayed.

TV. Tower data is replaced by fitting a urve to the accepted values, and substituting the value derivid from the curve for the rejected value. If too few points exist to generate a reasonable curve, the average value calculated for the reference height is adjusted to the level in question. If all TV readings for a particular type of variable are missing, the Height-Adjusted SRS Tower Average is used.

After the new values have been inserted the program calls Subroutine ARCPUT to write the 15 minute data to disk. Both the original and the corrected set of data is written to disk by ARCPUT. 


\section{CALLING SEQUENCE :}

Program called by ARCIVI at Û́, ij, 30, and 45 minutes sfter the hour. When finished, this program in turn calls program HRAV.

\section{INITIAIIZATION :}

This program reads averaged results from its last execution from file WD:ARCIV2.DAT as well as Bush Field data from Global Common ARCOM. In addition, the program uses Quality Assurance Flags set either by ARCIV1 subroutine ARCUBE or manual Flag setting Pgm FLAGS. These Flags are also located in Common ARCOM.

REAI TIME CONSIDERATIONS:

Program must complete execution pxior to beginning of the next 15 minute period. It normally takes about 4 seconds to execute. Event flag 35 is used (by subroutines COMGET and COMPUT) to secure access to Global Common ARCOM.

AUTHOR: M.M. Pendergast, ETD, Savannah River Lab, E.I. DuPont J.R. Froggatt, On-Line systems Group, ESD, E.I. DuPont

DATE: $12 / 82$

IAST REVISED: $1 / 88$

\section{ADDITIONAI REMARKS ON THE Q/A ALGORITHM:}

The $Q / A$ values computed during the last 15 min are used to replace SR tower data in the event that all towers are out. QA7TO is used to $Q / A$ the SR tower data. 1st, data screened by pgm ARCIV1 is flagged. Then $D 1$ data is saved and replaced with last $15 \mathrm{~min} Q / A$ values or Bush field values if last $Q / A$ values are 0. (NOTE: Bush field data is not height adjusted) Next the expected variation for speed is computed using previous Q/A speed and SIGA (per DP-1551). Then subroutine TEST is used to determine bad values and replace with avg. of remaining or last period ave. if all readings bad. Next $Q / A$ SIGE per DP-1551 using the just computed $Q / A$ speed average to determine expected SIGE variation. Next Q/A SIGA per DP-1551 again using current speed average. Now AZM is corrected. The first approximation of expected SIGA variation is set equal to the current value of the average SIGA value multiplied by the number of standard deviations allowed. This value is clamped to a maximum of $45 \mathrm{deg}$. Then plume meander is accounted for if current SIGE is less than 2 degrees. (NOTE: this supposedly applies during very stable conditions - this is not checked for). The plume meander is clamped at 90 degrees rather than the 30 degrees mentioned in DP-1551. Next, the latest stability class is calculated based on the current average value of SIGA. Finally, the 
Q/A values of D1 are computed. Using the current estimate of stability, the quality assured values of $\mathrm{D} 2$ are converted to

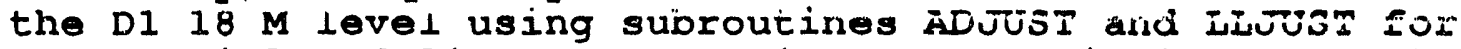
exponential and linear conversions respectively. Any values found to be incorrect are replaced with the corresponding D2 values using subroutine CHECK.

Now the TV tower is quality assured by QATVTO. 1st the temps. are converted from degrees $C$ to absolute. Then they are $Q / A^{\prime} d$. Per DP-1551, the expected variation is 5 degrees $C$, however, the program uses 10 deg. Subroutine TTFIX converts all temps to the $36 \mathrm{M}$ using subr. LIJUST. The bad values are flagged and replaced by subroutine TEST. These replacement values are overlayed with curve fitted values by subroutine TTCOR. This only occurs for points above $10 \mathrm{M}$ and only if three or more good points exist. Then a scheme is used to alter any corrected values above $10 \mathrm{M}$ taking potential temperature into consideration. Next, speed is $Q / A^{\prime} d$. The same formula is used as with the SR towers except the current SR tower speed, SIGA, and SIGE are used as opposed to last period. This was out of necessity the case with the SR towers. Subroutine TVFIX is called to identify the invalid data.

TVFIX is subsequently called for SIGA, SIGE, and AZM corrections. It is a general subroutine designed to correct different kinds of data. First it calls either ADJUST or LLJUST to convert the data to the $61 \mathrm{M}$ level. Then, COMPAR is called to flag invalid data (NOTE: COMPAR does not compare the values against each other but against the $\mathrm{Q} / \mathrm{A}$ SR tower average just computed). Then the bad values are replaced with the average of the remaining $T V$ values or the SR average if all TV values were bad. Then the replaced data is adjusted to the appropriate height using ADUUST or ILJUST. At this point control is returned to QATVTO. Currently all TV tower corrected values are overlayed by TVCOR (except TTCOR for temps) which supplies curve fitted values unless fewer than 3 good points exist. In this case, the corrected values stand as is.

After speed, SIGA and SIGE are corrected using the same formulas (and values in this case) as with the SR towers. TVFIX and TVCOR perform the calculations as was the case for speed corrections. The final speed values are clamped to no less than $0.2 \mathrm{M} / \mathrm{S}$ and the SIGA and SIGE values are restricted to lie between 0.1 and 90.0 .

Azimuths are handled nearly the same way that they are first run through the Kern/Pendergast algorithm to properly handle values in the 0 degree or 360 degree region. Then they are run through TVEIX and TVCOR. Then they are run through a MOD 360 operation to restrict values to $0-360$ deg.

Finally, temperatures are converted back from absolute to degrees $\mathrm{C}$. 
The main program then replaces the "number of points" variable

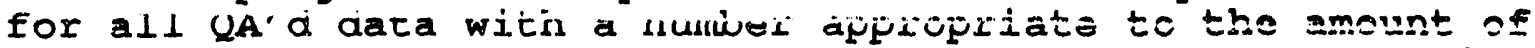
time that the machine was coliecting data ciuring the 15 minuto period (15 min $=600$ points).

The $U, V$ variables are then changed to agree with any AzM or speed corrections (COMPUT). Then the data is inserted into the data base by subroutine (ARCPUT).

\subsection{ARCPUT (ARCIV2 SUBR - Write 15 Minute Average Data To Disk)}

IDENTIFICATION :

Quality Assurance Program

NAME : ARCIV2

INSTALLED NAMES: ARCIV2

TYPE: WIND System Data Collection Program

EUNCTION :

This program is called at the end of every 15 minute period by data collection program ARCIV1. The program's purpose is to QUALITY Assure the data and then write it to disk using subroutine ARCRUT. Erroneous data is replaced with appropriate estimates. The Quality Assurance Algorithm implemented in the WIND System operates in two phases. The first phase consists of three schemes for determining invalid data, while the second phase is concerned with replacing the invalid data with estimated values.

Data is flagged as being invalid if an instrument is known to be out of service (done manually using pgm flags). In addititon, if less than $10 \%$ of the expected number of readings for a 15 minute period for a particular instrument are within the known ranges of the instrumentation, the data for that period and instrument is flagged (performed by ARCIV1 subroutine ARCUBF). The data that pass this initial screening is further checked against the average of all similar data items (e.g., all SRS Tower Azimuths). Any observation that differs by more than a specific amount from the mean is flagged, and a new mean is calculated from the remaining points. This procedure continues until an acceptable mean is computed that involves at least two instruments, or all of the observations are flagged.

The allowed deviation from the mean is a specified number of estimated standard deviations of the variable in question. 
The estimated standard deviations are calculated with empirical relationships based on meteorological conditions and statistical parameers, sucis as ftrmosparic stability and Sampling Period.

An additional consideration is required in Quality Controlling the data collected on the WJBF-TV Tower. Here the individual data points are compared to the mean values of like data items at different tower heights. In order to make meaningful comparisons, all data are adjusted to a common reference height. speed, siga, and sige are adjusted using power law rolationship while Temperature and Wind Direction are adjusted using a linear relationship. In all cases, equation parameters are used that have been empirically developed as a function of Atmospheric stability.

The second phase of the Quality Assurance Algorithm involves replacement of bad data with estimated values. For the SRS Towers, this merely consists of substituting the mean of the accepted values for the rejected data. If all values of a particular type have been rejected, the last available Average SRS Tower is used. However, if this is more than two hours old, adjusted data from Bush Field in nearby Angusta, Georgia are used. If Bush Field data is more than two hours old, no Quality Assurance is performed and a message to that effect is displayed.

TV Tower data is replaced by fitting a curve to the accepted values, and substituting the value derived from the curve for the rejected value. If too few points exist to generate a reasonable curve, the average value calculated for the reference height is adjusted to the level in question. If all TV readings for a particular type of variable are missing, the Height-Adjusted SRS Tower Average is used.

After the new values have been inserted the program calls Subroutine ARCPUT to write the 15 minute data to disk. Both the original and the corrected set of data is written to disk bY ARCPUT .

\section{CALLING SEQUENCE :}

Rrogram called by ARCIV1 at $00,15,30$, and 45 minutes after the hour. When finished, this program in turn calls program HRAV.

\section{INITIAIIZATION :}

This program reads averaged results from its last execution from file WD:ARCIV2.DAT as well as Bush Field data from Global Common ARCOM. In addition, the program uses Quality Assurance Flags set either by ARCIV1 subroutine ARCUBF or manual Flag setting Pgm FLAGS. These Flags are also located in Common ARCOM. 
REAL TIME CONSIDERATIONS :

Program must complete execution prior to beginning

of the next is minute period. It normally takes about 1

seconds to execute. Event flag 35 is used (by Subroutines COMGET and COMPUT) to secure access to Global Common

ARCOM.

AUTHOR: M.M. Pendergast, ETD, Savannah River Lab, E.I. DuPont J.R. Froggatt, On-Line Systems Group, ESD, E.I. DuRont

DATE : $12 / 82$

LAST REVISED: $1 / 88$

ADDITIONAI REMARKS ON THE Q/A ALGORITHM:

The $Q / A$ values computed during the last $15 \mathrm{~min}$ are used to replace SR tower data in the event that all towers are out. QA7TO is used to $Q / A$ the SR tower data. 1st, data screened by pgm ARCIV1 is flagged. Then D1 data is saved and replaced with last $15 \mathrm{~min} Q / \mathrm{A}$ values or Bush field values if last $\mathrm{Q} / \mathrm{A}$ values are 0. (NOTE: Bush field data is not height adjusted) Next the expected variation for speed is computed using previous $Q / A$ speed and SIGA (per DP-1551). Then subroutine TEST is used to determine bad values and replace with avg. of remaining or last period ave. if all readings bad. Next Q/A SIGE per DP-1551 using the just computed Q/A speed average to determine expected SIGE variation. Next Q/A SIGA per DP-1551 again using current speed average. Now AZM is corrected. The first approximation of expected SIGA variation is set equal to the current value of the average SIGA value multiplied by the number of standard deviations allowed. This value is clamped to a maximum of $45 \mathrm{deg}$. Then plume meander is accounted for if current SIGE is less than 2 degrees. (NOTE: this supposedly applies during very stable conditions - this is not checked for). The plume meander is clamped at 90 degrees rather than the 30 degrees mentioned in DP-1551. Next, the latest stability class is calculated based on the current average value of SIGA. Finally, the $Q / A$ values of $D 1$ are computed. Using the current estimate of stability, the quality assured values of $\mathrm{D} 2$ are converted to the D1 $18 \mathrm{M}$ level using subroutines ADJUST and LLJUST for exponential and linear conversions respectively. Any values found to be incorrect are replaced with the corresponding D2 values using subroutine CHECK.

Now the TV tower is quality assured by QATVTO. 1st the temps. are converted from degrees $C$ to absolute. Then they are Q/A'd. Per DP-1551, the expected variation is 5 degrees $C$, however, the program uses 10 deg. Subroutine TTEIX converts all temps to the $36 \mathrm{M}$ using subr. ILJUST. The bad values are flagged and replaced by subroutine TEST. These replacement values are overlayed with curve fitted values by subroutine TTCOR. This only occurs for points above $10 \mathrm{M}$ and only if three or more good points exist. Then a scheme is used to alter any corrected values above $10 \mathrm{M}$ taking potential temperature 
into consideration. Next, speed is $Q / A^{\prime} d$. The same formula is used as with the SR towers except the current SR tower speed, SIGA, and SIGLi are used as oppused to iast perild. This was out of necessity the case with the SR towers. Subruutine TVTIX is called to identify the invalid data.

TVEIX is subsequently called for SIGA, SIGE, and AzM corrections. It is a general subroutine designed to correct different kinds of data. First it calls either ADJUST or LLJUST to convert the data to the $61 \mathrm{M}$ level. Then, COMPAR is called to flag invalid data (NOTE: COMPAR does not compare the values against each other but against the $Q / A$ SR tower average just computed). Then the bad values are replaced with the average of the remaining TV values or the SR average if all TV values were bad. Then the replaced data is adjusted to the appropriate height using ADJUST or LLJUST. At this point control is returned to QATVTO. Currently all TV tower corrected values are overlayed by TVCOR (except TTCOR for temps) which supplies curve fitted values unless fewer than 3 good points exist. In this case, the corrected values stand as is.

After speed, SIGA and SIGE are corrected using the same formulas (and values in this case) as with the SR towers. TVEIX and TVCOR perform the calculations as was the case for speed corrections. The final speed values are clamped to no less than $0.2 \mathrm{M} / \mathrm{S}$ and the SIGA and SIGE values are restricted to lie between 0.1 and 90.0 .

Azimuths are handled nearly the same way that they are first run through the Kern/Pendergast algorithm to properly handle values in the 0 degree or 360 degree region. Then they are run through TVFIX and TVCOR. Then they are run through a MOD 360 operation to restrict values to $0-360 \mathrm{deg}$.

Finally, temperatures are converted back from absolute to degrees $\mathrm{C}$.

The main program then replaces the "number of points" variable for all $Q^{\prime}$ 'd data with a number appropriate to the amount of time that the machine was collecting data during the 15 minute period $(15 \mathrm{~min}=600$ points $)$.

The $U, V$ variables are then changed to agree with any AzM or speed corrections (COMPUT). Then the data is inserted into the data base by subroutine (ARCPUT). 
1.13 T_SWITCH SET (Set $T$-Switches To Allow Data Collection By Selected Cömputer)

IDENTIEICATION :

Archiving system $\mathrm{T}$-Switch set program

NAME : TSWITCH

INSTALLED NAMES: SWNORM/SWINDI/SWIND2

TYPE: WIND system general support program

EUNCTION :

The program functions as a foreign command and switches the T-Switches directing data and terminal lines to either of the two WIND System VAX computers. If the command line contains "SWNORM" then the normal switch settings on T SWITCH 1 of (0-7) go to $A$ (WIND2::) and $(8-15)$ go to $B$ (WIND1::5. The ñormal switch settings on T SWITCH 2 are all switches set to A (WIND2::). If the the command line contains "SWIND2" then all switches are set to $A$ on both $T$ switches and if the command line contains "SWIND2" all switches are set to $B$ on both $T$ switches.

INITIATION :

Program is requested for execution from a terminal by typing SWNORM, SWIND1, or SWIND2 to switch the A/B switches as described above.

AUTHOR: J.R. Froggatt, Process Systems Group, ESD, E. I. DuPont

DATE : $2 / 14 / 85$

LAST MODIFIED: $9 / 15 / 88$

1.14 HRAV (Update WD:HRAIX1/2.DAT File For Plots / Calcs Requiring Hourly Data)

NAME : FIRAV

FUNCTION: Create data for plots and calculations requiring hourly data TYPE: WIND System Data Collection Program

FUNCTION DESCRIPTION:

This program obtains data from the last four 15 minute records stored by the WIND system in either file WD:ARCDT1.DAT or WD:ARCDT2.DAT. The program updates file WD:TVSVDT.DAT which that can then be accessed by a number of downstream programs. This program also calls subroutine HRIXUP to update the current week's hourly SAM File (WD: HRAIX1.DAT OR WD: HRAIX2.DAT). The current week's SAM file is used by program HRAVPT for plotting the plume of an actual or hypothetical release. The program then opens and closes SLEOC1::[WIND_GET]LOGIN.COM to allow that system to 
copy over files that could be used for emergency response calculations in the event that communications were cut between hoth WIND SYSTEM VAX's and the EUC V̈̈̈.

Routine modified $3 / 87$ to write file WD:WIND_EOC.DAT containing current system time along with time of last WIND data stored on current system. This data will be used by SLEOC1: : to set it's time equal to that of current system. The time of the last data stored will be used by WD:WIND EOC: : to determine which archiving files to access (WD:HRAIXI.DAT and WD:ARCDT1.DAT Or WD: HRAIX2.DAT and WD:ARCDT2.DAT) .

\section{INITIATION :}

Program initiated by ARCIV2 every 15 minutes after it has updated file WD:ARCDT1.DAT or WD:ARCDT2.DAT at $0,15,30$, and 45 minutes after the hour.

REAL TIME CONSIDERATIONS:

Precaution is taken using the Lock Manager to secure exclusive access to the various data files used.

AUTHOR: J.R. Froggatt, Process Computer Services Group, ESD, E.I. DuPont

DATE: $6 / 15 / 83$

LAST MODIFIED: $2 / 21 / 89$

1.15 HRAV1 (Program To Update TEST Hourly SAM File WA: SAMYYYYmm.DATA)

NAME : HRAV1

FUNCTION: TEST program to update indexed sequential hour avg file TYPE: WIND System Data Collection Program

FUNCTION DESCRIPTION:

This TEST program obtains data from the last four 15 minute records stored by the WIND System in either file WD:ARCDT1.DAT or WD:ARCDT2.DAT. It then calls subroutine HRIXUP to update the current months's hourly indexed sequential SAM File (WA: SAMYYYYMm.DAT).

INITIATION :

Program initiated by HRAV every 15 minutes after it has updated the weekly (actual production file) SAM file WD: HRAIX2.DAT or WD: HRAIX2.DAT at $0,15,30$, and 45 minutes after the hour. 
REAI TIME CONSIDERATIONS:

Precaution is taken using tine Jock Manayer to secuite exclusive access to the various data files used.

DATE : $11 / 85$

1.16 SAMUP (HRAV1 SUBR - Update WA: SAMYYYYmm.DAT With Data Supplied By HRAV1)

IDENT IFICATION :

Subroutine to update SAM file

NAME : SAMUP

TYPE: HRAV1 Subroutine

FUNCTION :

This subroutine is called by pr am HRAV1 to update the hourly SAM file. Subroutine SAMLOC is called to determine which file (WA: SAMYYYYmm.DAT) is to be used and which record within it (key = YYYYmmddhh0000.00) is to be written. The data which has been passed by HRAV1 is then written into the correct record of the file.

CALLING SEQUENCE :

Subroutine is called by program HRAV1. This subroutine calls subroutine SAMLOC.

REAL TIME CONSIDERATIONS :

Lock 'WA:SAMYYYYmm.DAT' is used to obtain exclusive access to the whatever month's SAM file (WA:SAMYYYYmm.DAT) is being updated. This is to avoid file contention with any program attempting to correct or retrieve data from the file.

AUTHOR: J.R. Eroggatt, On-Line Systems Group, ESD, E.I. DuPont DATE : $6 / 84$

1.17 SAMLOC (HRAV1 SUBR - Determine File Name And Rec Key FOr WA:SAMYYYYmm.DAT) IDENT IF ICATION :

Calculate file name and record key of next SAM file entry 
NAME : SAMLOC

TYPE: HRAV1 subroutine

FUNCTION :

Subroutine determines file name (WA:SAMYYYymm.DAT) and record key (YYYymmddhh0000.00) of of next record to write into current month"s SAM data file. It uses the date and time supplied to it by the calling program to do this.

CALIING SEQUENCE :

Called by subroutine SAMUP which in turn is called by HRAVI. AUTHOR: J.R. Froggatt, on Line systems Group, ESD, E.I. DuPont DATE : $6 / 19 / 84$

1.18 INCKEY (HRAV1 SUBR - Increment Key For TEST SAM File WA:SAMYYYYMm.DAT)

\section{IDENT IF ICATION :}

Subroutine to update SAM file

NAME : SAMUP

TYPE: HRAV1 Subroutine

FUNCTION :

This subroutine is called by program HRAV1 to update the hourly SAM file. Subroutine SAMLOC is called to determine which file (WA: SAMYYYYmm.DAT) is to be used and which record within it (key $=$ YYYYmmddhh0000.00) is to be written. The data which has been passed by HRAVl is then written into the correct record of the file.

CALLING SEQUENCE :

Subroutine is called by program HRAV1. This subroutine calls subroutine SAMLOC.

REAL TIME CONSIDERATIONS:

Lock 'WA: SAMYYYYmm.DAT' is used to obtain exclusive access to the whatever month's SAM file (WA: SAMYYYymm.DAT) is being updated. This is to avoid file contention with any program attempting to correct or retrieve data from the file.

AUTHOR: J.R. Froggatt, On-Line Systems Group, ESD, E.I. DuPont DATE : $6 / 84$ 


\subsection{ZEROAC (Zero Out Previous Week's Archiving Files)}

NAME : ZEROAC

FUNCTION: zero out previous week's Archiving files.

TYPE: WIND System Data Collection Prosram

FUNCTION DESCRIPTION :

This program runs every day and first determines the current day of the week. If it is Sunday - Wednesday, the program copies the previous week's SAM average file to directory [WIND.ARCH] (WA:) and exits. This is done four times in case the machine is down at some point.

If it is Thursday - Saturday, the program zeroes

out the previous week's Archive file (WD:ARCDT1.DAT or WD:ARCDT2.DAT). In addition, the program zeros out the previous week's SAM Average file (WD:HRAIX1.DAT or

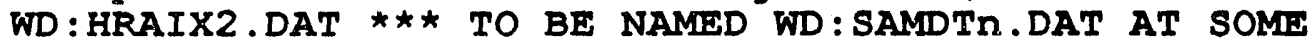
FUTURE DATE***). The program zeros out the previous week' s files on Thursday - Saturday to insure that this is accomplished even though the machine may be down at the time some of the runs of this program are scheduled. Added protection can be achieved by running the program more than once a day and/or by calling for its execution in the startup file.

INITIATION: Scheduled as repetitive process at system Boot time AUTHOR: J.R. Froggatt, on Line Systems Group, ESD, E.I. Dupont DATE: $6 / 8 / 83$

LAST REVISED: $1 / 89$ 
CHAPTER 2

* EOC DATA COLLECTIOIN RROGRAMS $+\frac{4}{4}$

2.1 ARCIV_EOC (Insert Data From SLWND:: Cluster Into EOC UVAX SLEOC1:: Files)

IDENTIE ICATION :

PROGRAM TO WRITE CURRENT 15 MINUTE ARCHIVING RECORD ON EOC VAX

NAME : ARCIV_EOC

TYPE: WIND SYSTEM DATA COLLECTION PROGRAM

FUNCTION :

This program is run every 15 minutes on SLEOC1:: and reads file WD:ARCIV EOC.DAT which has just been copied over from one of the two WIND system VAX's (SLWND1:: or SLWND2::). The file is two records long and contains the header record and current 15 minute data record from the current 15 minute wIND system file WD:ARCDT1.DAT or WD:ARCDT2.DAT. This program will insert the data into WD:ARCDT1.DAT or WD:ARCDT2.DAT on SLEOC1:: Then the header records of the updated files will be updated to reflect the data just inserted.

$\star \star \star \star$ FUTURE FEATURE $\star \star \star \star ~$

This program will then compare the two header records to see if data on SLEOC1:: is as complete as that on the WIND system. If not, the most current missing four or less records will be retrieved and inserted into the file on SLEOC1:: . If more then four records are missing, an additional four or less records will be retrieved during the next run of this program in 15 minutes.

CALLING SEQUENCE:

Program execution is requested every $15 \mathrm{~min}$ at $00,15,30$, and 45 minutes after the hour by SLEOC1: : [WIND GET] LOGIN. COM which is initiated by SLWND1: : unless that system is down. In that case, it is initiated by SLWND2:: if that system is up. 
REAI TIME CONSIDERATIONS:

Program must complete execution prior to the beginning of the next 15 minute period. It normally takes less than five seconds to execute. No consideration is given to file contention since VMS allows multiple access to sequential files. Also, this program only reads data from SLWND: : and is the only program writing to WD:ARCDT1.DAT or WD:ARCDT2 .DAT On SLEOC1: : .

AUTHOR: J.R. Froggatt, Process Computer Services Group, ESD, E.I. DuPont DATE : $3 / 19 / 87$

REVISED : $1 / 89$

2.2 TIMESET_EOC (Set Time On EOC UVAX SLEOC1:: TO That of SLWND:: Cluster)

\section{IDENT IE ICATION :}

PROGRAM TO SET TIME ON SLEOC1:: TO TIME FOUND IN SLEOC::WD:WIND_EOC.DAT NAME : TIMESET_EOC

TYPE: PROGRAM TO FACILITATE DATA GATHERING

FUNCTION :

This program was developed to allow EOC VAX SLEOC1: : to read SLEOC1::WD:WIND_EOC.DAT which contains the current time of the calling system (SLWND1:: or SLWND2::) and set SLEOC1:: time equal to it. SLEOC1::WD:WIND_EOC.DAT also contains the time and date of the last WIND daEa stored on the calling machine. This allows SLEOC1:: to determine the names of the WIND data files (IRCDT1.DAT and HRAIX1.DAT or ARCDT2.DAT and HRAIX2.DAT) that must be kept in sync between SIEOC1:: and the calling system.

CALIING SEQUENCE: Called bY SLEOC1:: SRLUSER:[WIND_GET]LOGIN.COM if login being made via mode "NETWORK".

AUTHOR: J.R. Froggatt, Process Computer Services Group, ESD, E.I. DuPont DATE : $3 / 17 / 87$ 
2.3 ZEROAC_EOC (Zero Out Previous Week's Archiving Files On EOC UVAX SIEOC1::)

NAME : TEROAC_EOC

FUNCTION: zaro out previous reek's Archiving files on EGC VAX.

TYPE: WIND System Data Collection Program (EOC version).

FUNCTION DESCRIPTION :

This program runs every day and first determines the current

day of the week. If it is Sunday - Wednesday, the program exits.

If it is Thursday - Saturday, the program zercies

out the previous week's 'irchive file (WD:ARCDI'1.DAT

or WD:ARCDT2.DAT). In addition, the program zeros out

the previous wek's SAM Average Eile (WD:HRAIXI.DAT or

WD:HRAIX2.DAT). The program zeros out the previous week's files

on Thursday - Saturday to insure that this is accompliahed

even though the machine may be down at the time some of

the runs of this progrem are scheduled. Added protection

can be achieved by running the program more than once a day

and/or by calling for its orecution in the startup file.

INITIATION: Scheduled as repetitive Prucess at system Boot time

AUTHOR: J.R. Froggatt, Process Computer Services Group, ESD, E.I. Dupont

DATE: $3 / 11 / 87$

LAST MODIFIEL : $1 / 89$ 


\section{CHAPTER 3}

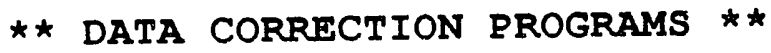




\section{CHAPTER 4}

** DATA RETRLEVAT PROGRÄis **

4.1 ARCLST (Generate Listing of Archived 15 Minute Meteorological Data)

IDENTIEICATION: Program to list TV, SRS Twr, and Clim Twr Data

NAME : ARCLST

TYPE: Archive Retrieval Program

EUNCTION :

This program obtains data from the WIND system Archive File beginning at the time and date specified at the keyboard. It acquires information from file WD:ARCDT1/2.DAT using data from 1 - 9615 minute periods as requested at the keyboard. It then calls subroutine ARCWRT (or CLMWRT if Central Climatology Data was requested) to list the data. The program then collects data from the next 1 - 96 records and again calls subroutine ARCWRT (or CLMWRT). This process continues until either the data from the WIND system Archive file is exhausted or the requested number of listings has been generated.

AUTHOR: J.R. Froggatt, On-Line Systems Group, ESD, E.I. DuPont DATE: $3 / 82$

LAST REVISED: $11 / 87$

4.2 ARCWRT (ARCLST SUBR - Format And Write TV And SRS Tower Data)

IDENTIEICATION: Routine to list archived data

NAME: ARCWRT

TYPE: ARCLST Subroutine 
FUNCTION :

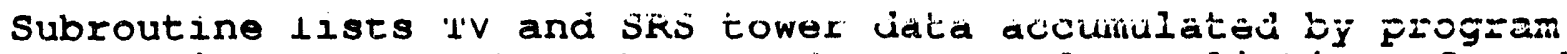
ARCLST in response to a keyboard request for a listing or arohived data.

AUTHOR: J.R. Froggatt, On-Iine systems Group, ESD, E.I. DuPont DATE : $3 / 82$

LAST REVISED: $11 / 87$

4.3 CLMWRT (ARCLST SUBR - Format And Write Central Climatology Tower Data) IDENTIFICATION: Routine to list archived data

NAME : CLMWRT

TYPE: ARCLST Subroutine

FUNCTION :

Subroutine lists Central Climatology Data accumulated by program ARCLST in response to a keyboard request for a listing of archived data.

AUTHOR: J.R. Froggatt, Process Systems Group, ESD, E.I. DuPont DATE : $11 / 14 / 85$

4.4 MATLST (Generate ASCII Formatted File of Archived 15 Minute Met Data) IDENTIEICATION: Program to format and write archived data to a file

NAME : MATLST

TYPE: WIND System Data Retrieval Program

FUNCTION :

This program obtains data from the WIND System Archive Eile beginning at the time and date specified at the keyboard. It acquires information from file WD:ARCDT1/2.DAT using data from 1 - 9615 minute periods as requested at the keyboard. It then calls subroutine MATWRT to list the data on printer and write to disk. The program then collects data from the next $1-96$ 
records and again calls subroutine MATWRT. This process continues until either the data from the WIND system Archive file is

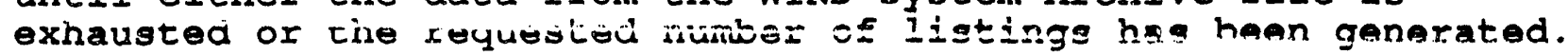
AUTHOR: J.R. Froggatt, on Line Systems Group, ESD, E.I. DuPont DATE : $12 / 83$

LAST REVISED: $2 / 89$

\subsection{MATWRT (MATLST SUBR - Write Data Supplied By MATLST TO Disk)}

IDENTIEICATION: Subroutine to format and write archived data to a file

NAME : MATWRT

TYPE: MATLST Subroutine

FUNCTION :

This subroutine formats WIND System Archive Data accumulated by program calling program MATLST and writes it to a disk file. The information is written in ASCII form to 80 character fixed length records. This makes the data easy to read on almost any other system. Program MATLST, supplies data to this routine in response to a keyboard request specifying the specific archived data that is required.

AUTHOR: J.R. Froggatt, on Line Systems Group, ESD, E.I. DuPont DATE : $12 / 83$

LAST REVISED: $2 / 89$ 
CHAPTER 5

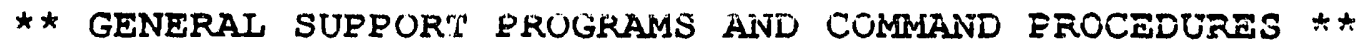

\subsection{ARCTAP (Transfer Archive/SAM Files Between Disk And Tape)}

NAME: ARCTAP.COM

EUNCTION: Transfer WIND System Files Between Disk and Tape or WORM disk

TYRE: WIND System General Support Procedure

\section{FUNCTION DESCRIPTION :}

This procedure will operate in either of four modes depending upon the value of a parameter supplied to it when it is initiated from a keyboard. If the parameter value begins "SAMTAP" the procedure will operate on SAM (Site Area Mean) data files. If the parameter is non-existant or if it is any other value, the procedure will operate on the main WIND syetem archiving files. The comments below generally apply to either mode that the procedure may be operating in. However, when a comment applies only to the main WIND system archiving files, the corresponding information pertaining to SAM data files follows immediately in parentheses.

This procedure will either transfer archived wIND system Archive (SAM) data from disk to tape or from tape back to disk into tape restore file WD:ARCDT3.DAT (WD:HRAIX3.DAT). If it is requested that data be transferred to tape, the procedure will dump the previous week's Archive (SAM) File to tape. This will be either WD:ARCDT1.DAT or WD:ARCDT2.DAT (WD:HRAIX1.DAT or WD:HRAIX2.DAT) depending upon which of those two alternating fjles is currently being used to store Archive (SAM) Data. Program FILSEL is called to determine which file was used last week and what the name of the mag tape file should be. The mag tape file will be named ARCyymmdd.DAT (SAMyymmdd.DAT) where yymmdd represents the the date of sunday of last week. This is the lst date of data storage for that week. In addition to dumping and retrieving tape data, the procedure is also able to provide a directory of the files on tape. It can also rerun a dump operation if the lst one was done incorrectly. 
It is also able to overlay the previous week's disk data file with the corresponding tape file (as opposed to writing it into tape restore vile WD:ARCET3.DAT (WD:HRAIX3.DAT)).

The procedure is able to store 2 month's (2 year's) data on a $1200 \mathrm{ft}$ tape and 4 month's (4 year's) data on a $2400 \mathrm{ft}$ tape at a density of $1600 \mathrm{BPI}$. The procedure has been modified to use the new tape drive and writes to tape at a density of $6250 \mathrm{BRT}$. However, the new data file record format has changed from 6 block records for a 15 minute time period to 15 block records. The amount of data that can be stored on tape under these circumstances has not yet been determined as of 12/07/88. The procedure asks whether the tape to be written to is new or old. If new, it asks for confirmation that it is ok to write over all existing tape data. If so, the dump proceeds. If the tape is old, it already has at least one week's data on it. In this case, the procedure asks for confirmation that it is ok to add a new data file to the end of the tape. If so, the procedure by default advances to the end of the data already existing on the tape and proceeds to add the new data. However, if it is desired to skip over a user specified number of files before writing, this can be accomplished by the proper keyboard input.

It is suggested that FILECK be run in conjunction with the dumping operation. That program reads the header records of the Archiving Files (same info from EIIECK applies to SAM tapes) and indicates the time span covered by each and what data if any is missing. The portion of this information that applies to the previous week's file should be kept with the tape as a record of the data stored on it.

If it is desired to restore tape data to disk, the procedure will ask the name of the file to be retrieved. File names correspond to the beginning date stored in each file (eg. ARC890108.DAT (SAM890108.DAT)). Each set of data starts on a Sunday. Even if Sunday data is missing due to system outage, the data file is still named for that sunday. The procedure will ask for confirmation that it is ok to write to disk. If so, the data will be written to tape restore file WD:ARCDT3.DAT (WD:HRAIX3.DAT). This file can then be accessed by ARCDSP (PLMDSP) to generate plots of the data. There is one exception to the way data is restored from tape. If the data is from before $01 / 01 / 89$, then it was stored on tape without Central Climatology or Area Tower Temperature data. In this case, this procedure first restores the data to the short format file WD:ARCIX3.DAT. It then runs the conversion program IX3 TO DT3 to read the data from WD:ARCIX3.DAT and output the data to WD:ARCDT3.DAT in expanded format. Zeroes will appear in the WD:ARCDT3.DAT file where Climatology or Area Temperture data would normally be found. Although it is not prompted for, if an operation of $(0)$ verlay is specified instead of (RE) store, the tape data will overlay the previous week's Archive (SAM) File WD:ARCDT1.DAT Or WD:ARCDT2.DAT (WD: HRAIX1.DAT or WD: HRAIX2.DAT) 
rather than the tape restore file. This is not prompted for because it is not likely to be required very often and because it has the potential of destroying the previous week's data.

INITIATION : Keyboard Request

\section{INITIALIZATION :}

Through keyboard dialog, the procedure is supplied with the information required to perform the desired operation.

AUTHOR: J.R. Froggatt, On-Line Systems Group, ESD, E.I. DuPont

DATE : $9 / 24 / 82$

LAST MODIFIED : $1 / 89$

5.2 COEF_CL (Update Engr Units Conversion Coefficient File - Cent Climatology)

\section{IDENT IF ICATION :}

Program to keyboard adjust Central Climatology coefficients

NAME: COEF_CL

INSTALLED NAMES: COEF_CL

TYPE: WIND System general support program

FUNCTION :

This program displays and allows the alteration of the engineering units calculation coefficients contained in WD:COEF CL.DAT. The values are read by ARCIV1 subroutine ARCINI when ARCIV1 begins execution. After values are modified by this program and inserted into WD:COEF_CL, the user is given the option of also modifying the coefficients as they appear in common ARCOM CL. This eliminates the need to stop and start ARCIV1 in order to allow the coefficients to be used. However, this must be done on both SLWND1 and SLWND2 since either machine may collect data depending upon whether the primary data collection machine (SLWND2) or the standby data collection machine (SLWND1) is performing data collection.

INITIATION :

The program is initiated from a terminal.

REAL TIME CONSIDERATIONS :

In ordex to put changes into common ARCOM_CL without 
restarting ARCIV1, the modify memory option of this program may be used when running it on both SLWND1:: and SLWND2: : .

AUTHOR: J.R. Froggatt, Process Systeins Group, ESD, E.I. DuEont

DATE : $11 / 6 / 85$

5.3 COEF_TP (Update Engr Units Conversion Coefficient File - SRS Twr Temps)

IDENTIF ICATION :

Program to keyboard adjust Met tower temperature coefficients

NAME : COEF_TP

INSTALIED NAMES: COEF_TP

TYPE: WIND system general support program

FUNCTION :

This program displays and allows the alteration of the engineering units calculation coefficients contained in WD:COEF TP.DAT. The values are read by ARCIV1 subroutine ARCINI when ARCIV1 begins execution. After values are modified by this program and inserted into WD:COEF TP, the user is given the option of also modifying the coefficients as they appear in common ARCOM TP. This eliminates the need to stop and start ARCIV1 in order to allow the coefficients to be used. However, this must be done on both WIND1:: and WIND2:: since either machine may collect data depending upon whether the primary data collection machine (WIND2::) or the standby data collection machine (WIND1::) is performing data collection.

INITIATION :

The program is initiated from a terminal.

REAL TIME CONSIDERATIONS:

Corrections made on WIND2: : will be copied to WIND1:: at the end of the current 15 minute interval although the changes will not be read by ARCIV1 on that machine until the program is restarted. In order to put changes into common ARCOM TP without restarting ARCIV1, the modify memory option of this program may be used when running it on both WIND1:: and WIND2::

AUTHOR: J.R. Froggatt, Process Computer Services Group, ESD, E.I. DuPont DATE : $9 / 11 / 87$ 


\subsection{FILSEL (Determine Disk And Tape File Names For Procedure ARCTAP)}

NAME : FILSEL

FUNCTION: Determine tape/disk file names corresponding to prev week TYPE: WIND System general support program

FUNCTION DESCRIPTION :

This program determines which file was used by the Archiving system during the previous week ( 1 or 2 ) and the date of the beginning data (Sunday of previous week). It communicates with the calling command procedure (ARCTAP running in ARCTAP, SAMTAP, ARCWRM, or SAMWRM mode depending on whether regulax WIND 15 minute files or SAM average files are being handled and whether tape or WORM disk is being used) thru the use of logical name assignments. Output is in the form of three process logical name assignments. The error code $(0$ or 1$)$, disk file number (1 or 2) of the file used the previous week, and the date of the Sunday of that week (yymmdd) are returned respectively thru logical name equivalence assignments to LOGICAL_ERROR_INDICATOR LOGICAL FILE NO, and LOGICAL FILE DATE.

The calIing procedure then us̄es this information to transfer files between disk and tape. For example, if the calling procedure is ARCTAP (ARCTAP running in ARCTAP mode), it can upon request transfer last week's Archive file (WD:ARCDT1.DAT or WD:ARCDT2.DAT) to tape or WORM disk with the name reflecting the date of the Sunday (lst day) of that week (ARCH\$DEV:ARCyymmdd.DAT). The date will always be of Sunday even if there are gaps in the data and actual data does not begin until later in the week.

\section{INITIATION :}

Program is initiated by disk/tape (or WORM disk) transfer procedure ARCTAP.COM which has been invoked to act as ARCTAP, SAMTAP, ARCWRM, OI SAMTR: :

\section{CALLING SEQUENCE :}

The program calls subroutine INXCLC to determine which disk file is being used during the current week and therefore which was used the previous week ( 1 or 2 ). It then calls subroutine TIMCLC to determine the 1st day of the previous week. Although the results would be the same regardless of whether one of the regular archiving files is accessed (WD:ARCDT1.DAT or WD:ARCDT2.DAT) or one of the SAM files is accessed (WD:HRAIX1.DAT or WD:HRAIX2.DAT), for consistency the file appropriate to the calling procedure (ARCXXX or SAMXXX) is the one that is accessed for this information. INITIALIZATION :

This program determines whether it was called by ARCTAP, SAMTAP, 
ARCWRM, or SAMWRM (actually ARCTAP.COM acting as ARCXXx or SAMXXX depending upon how it was invoked) by determining the equivalence

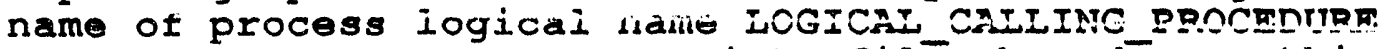

It then accesses the appropriate filës based lipon this information.

REAL TIME CONSIDERATIONS: N/A

AUTHOR: J.R. Froggatt, On-Line Systems Group, ESD, E.I. DuRont

DATE : $10 / 01 / 82$

LAST MODIFIED : $1 / 89$

5.5 FLAGS (Display And Set Q/A Flags To Indicate Instrumentout of Service)

IDENTIFICATION :

Program to keyboard adjust quality assurance flags

NAME : FLAGS

INSTALLED NAMES: FLAGS

TYPE: WIND System general support program

FUNCTION :

This program displays and allows the alteration of the quality assurance flags that exist in global commons ARCOM, ARCOM TP, and ARCOM CL. The flags are set by ARCIV1 subroutine $A R C U B \bar{F}$ at the end of each 15 minute interval. These flags are subsequently used by ARCIV2 to make decisions concerning estimated data that is substituted for readings that are considered to be in error. The flag values are then written to disk by ARCIV3 along with all the data collected in the 15 minute period. In addition, the flags are written to disk file WD:ARCQTY.DAT by ARCIV3. This allows ARCIV1 to read the last saved values of the flags when beginning execution during a system boot or at any other time that it begins operation.

INITIATION :

The program is initiated from a terminal. It displays current flag values and prompts for either corrections or CTRL/z for program termination. An example correction entry is supplied to the user. When a correction is made the entire set of flags is again displayed to allow verification of proper handling of the correcting entry.

REAL TIME CONSIDERATIONS:

Corrections made will be reflected in the above mentioned files 
after the current 15 minute period has ended.

AUTHOR: J.R. Hroggaic, OA Line systoms Group, RSD; E.I. DuPont

DATE : $9 / 25 / 80$

REVISED: $11 / 13 / 85$

REVISED : $10 / 29 / 87$

5.6 IX3_TO_DT3 (COPY WD:ARCIX3.DAT TO WD:ARCDT3.DAT EOr PrOcedure ARCTAP)

NAME : FIISEL

FUNCTION: Determine tape/disk file names corresponding to prev week

TYPE: WIND system general support program

FUNCTION DESCRIPTION :

This program determines which file was used by the Archiving system during the previous week (1 or 2) and the date of the beginning data (Sunday of previous week). It communicates with the calling command procedure (ARCTAP running in ARCTAP, SAMTAP, ARCWRM, Or SAMWRM mode depending on whether regular WIND 15 minute files or SAM average files are being handled and whether tape or WORM disk is being used) thru the use of logical name assignments. Output is in the form of three process logical name assignments. The error code ( 0 or 1 ), disk file number (1 or 2) of the file used the previous week, and the date of the Sunday of that week (yymmdd) are returned respectively thru logical name equivalence assignments to LOGICAL_ERROR_INDICATOR LOGICAI FILE NO, and LOGICAI EILE DATE.

The calIing procedure then usses this information to transfer files between disk and tape. For example, if the calling procedure is ARCTAP (ARCTAP running in ARCTAP mode), it can upon request transfer last week's Archive file (WD:ARCDT1.DAT or WD:ARCDT2.DAT) to tape or WORM disk with the name reflecting the date of the Sunday (1st day) of that week (ARCH\$DEV:ARCyymmdd.DAT). The date will always be of Sunday even if there are gaps in the data and actual data does not begin until later in the week.

INITIATION :

Program is initiated by disk/tape (or WORM disk) transfer proceduxe ARC'TAP. COM which has been invoked to act as ARCTAP, SAMTAP, ARCWRM, OF SAMWRM.

\section{CAILING SEQUENCE:}

The program calls subroutine INXCLC to determine which diak file is being used during the current week and therefore which was used the previous week ( 1 or 2 ). It then calls subroutine 
TIMCLC to determine the 1st day of the previous week. Although the results would be the same regardless of whether one of the

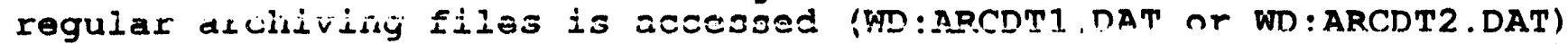
or one of the SAM files is accessed (WD:IRAIX1.DAT or WD:HRAIX2,DAT), for consistency the file appropriate to the calling procedure (ARCXXX or SAMXXX) is the one that is accessed for this information.

INITIALIZATION :

This program determines whether it was called by ARCTAP, SAMTAP, ARCWRM, or SAMWRM (actually ARCTAP.COM acting as ARCXXx or SAMxXX depending upon how it was invoked) by determining the equivalence name of process logical name LOGICAL_CALIING_PROCEDURE.

It then accesses the appropriate files based upon this information.

REAL TIME CONSIDERATIONS: N/A

AUTHOR: J.R. Froggatt, On-Iine Systems Group, ESD, E.I. DuPont

DATE: $10 / 01 / 82$

LAST MODIFIED : $1 / 89$

5.7 RDAGS (Create Bush Field Data File WD:AGSDAT.DAT)

NAME: RDAGS

FUNCTION: Acquire Bush Field AFOS Data and prepare for WIND system

TYPE: WIND Syatem General Support Program

FUNCTION DESCRIPTION:

This program is a modification and combination of program RDSAO written by R.J. FAUST and PDP 11 program AGSDAT written by M.M. Pendergast and COOP student G. Green. The purpose of the program is to obtain hourly Bush Field data from the vAX based AFOs file and format it to allow easy retrieval. Input is acquired from file AD:SAO.DAT and output is written to WD:AGSDAT.DAT. (Program is run every 15 minutes to ensure that hourly Bush field data is made available soon after it is received.) Stability class is computed from Bush field observations and included with the observed data that is written to the output file. In addition, the pertinent data is inserted in Global Comon ARCOM.

INITIATION: Wakes from hibernation state every 15 minutes as set up at system boot time.

AUTHORS: R.J. Faust/M.M. Pendergast/J.R. Froggatt

DATE : $11 / 20 / 82$ 
5.8 SNAP (List Current Values For SRP Meterological Tower Readings)

IDENTIFICATION :

Archiving system TV, SR, TP, and CL tower data snapshot program

NAME : SNAP / MAC

INSTALLED NAMES: SNAP

TYPE: WIND System general support program

FUNCTION :

When operating in SNAP mode the program obtains last set of data acquired by ARCIV1 from global commons ARCOM, ARCOM TP, ARCOM TP and lists it on the terminal that initiated the program. Units will be English or metric depending on whether or not the string "ENGLIsH" appears on the command line used to invoke the program as a foreign command. If the program is operating in MAC mode (depending on whether or not the string "MAC" appears on the command line), it requests the area to report, the total number of times to report it:, and the frequency to report it (voltages only).

INITIATION :

Program is requested for execution from a terminal by typing MAC to acquire selective repetitive data or by typing SNAP to acquire a onetime overview of all SRS readings.

AUTHOR: J.R. Froggatt, On-Line Systems Group, ESD, E. I. DuPont DATE: $4 / 13 / 84$

REVISED: $11 / 12 / 85$

REVISED: $7 / 10 / 87$

REVISED : $10 / 30 / 87$ 


\section{CHAPTER 6}

* * GENERAL SUBROUTTINES $*$ *

6.1 HIXCLC (Calculate File And Record Number For WL: HRAIX1.DAT / WD:HRAIX2.DAT)

IDENTIF ICATION :

Calculate File and Record Number of Next Plume File Entry

NAME : HIXCLC

TYPE: HRAV Subroutine

FUNCTION :

Subroutine calculates index of next record to write into current week's plume data file (WD:HRAIX1.DAT or WD:HRAIX2.DAT) and which of the two files its current. It first calls subroutine INXCLC to determine which file and record would be used for the time and date of the data in the regular archiving system (fo- files WD:ARCDT1.DAT and WD:ARCDT2.DAT). The subroutine then adjusts the result to comply with HRAV file requirements.

CALLING SEQUENCE :

Called by subroutine HRIXUP which in turn is called by pgm HRAV. AUTHOR: J.R. Froggatt, On-Line Systems Group, ESD, E.I. DuPont DATE : $1 / 7 / 81$

6.2 HRIXUP (Insert Data Into WD: HRAIX1.DAT Or WD:HRAIX2.DAT)

IDENTIF ICATION :

Subroutine to Update Hour Average File

NAME : HRIXUP 


\section{TYPE: General Subroutine}

EUNCTION :

This subroutine is called by program HRAV or HRAVCR to update or correct the Hourly Plume File. Subroutine HIXCLC is called

to determine which file (WD:HRAIX1.DAT or WD:HRAIX2.DAT) is to be used and which record within it is to be written. The data, which has been passed by HRAV is then written into the correct record position of the proper file.

\section{CALLING SEQUENCE :}

Subroutine called by Program HRAV. Subroutine calls Subroutine HIXCLC.

REAL TIME CONSIDERATIONS :

The Lock Manager is used to obtain exclusive access to the Plume File being written into (WD:HRAIXI.DAT or WD: HRAIX2.DAT). This is to avoid file contention with any program attempting to correct data in the file or retrieve data from the file.

AUTHOR: J.R. Froggatt, On-Line systems Group, ESD, E.I. DuPont

DATE : $1 / 7 / 81$

LAST REVISED: $2 / 89$

\subsection{IJOCK (Grant Resource Lock)}

NAME: SUBROUTINE LOCK

FUNCTION: Subroutine to grant resource locks

TYPE: General subroutine

EUNCTION DESCRIPTION:

This subroutine locks a resource specified by the calling program thru the use of the lock manager. In addition to the resource name, the mode of the lock and a time limit in which to accomplish the locking function must be specified. This time limit will normally be expressed as a real number between 0.00 and 60.00 seconds. If the number is 0.00 or less, the value of 0.00 will be used. If the number is greater than 59.9, the subroutine will wait indefinitely for the lock to be granted. The subroutine will return a lock status block (a 6 longword array required to $\mathrm{DEQ}$ a lock), a lock id assigned by the system and required by any lock manager system service calls that subsequently reference the lock, a status indicating why a system call may have failed, and a genural 
subroutine status indicating overall success or failure of the subroutine. This variable will contain a 1 for successful completion and an $\Theta v e n$ suniüe for unsuccessfil completion indicating that the lock coula not be efrected and why.

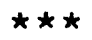

$\star * *$

$\star \star * *$

$\star \star \star *$

$\star \star \star$

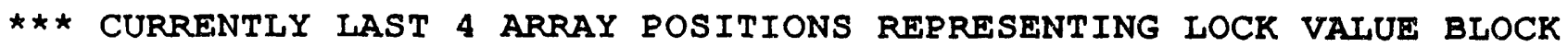
ARE NOT USED BY WIND SYSTEM AND ARE SET TO $O$ BY THIS SUBROUTINE. OCCASIONAL SYSTEM HANGUPS WERE EXPERIENCED WITH "\&SYSTEM-W-VALNOTVALID, value block is not valid" ERROR CODE 2544 ERRORS WHEN LOCK VALUE BLOCK

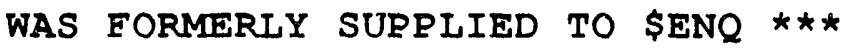

ARGUMENTS :

NAME

RESOURCE

IOCK MODE

TIME LIMIT

LOCK_STATUS O

IOCK ID
I

$I / 0$

I

I

0

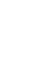




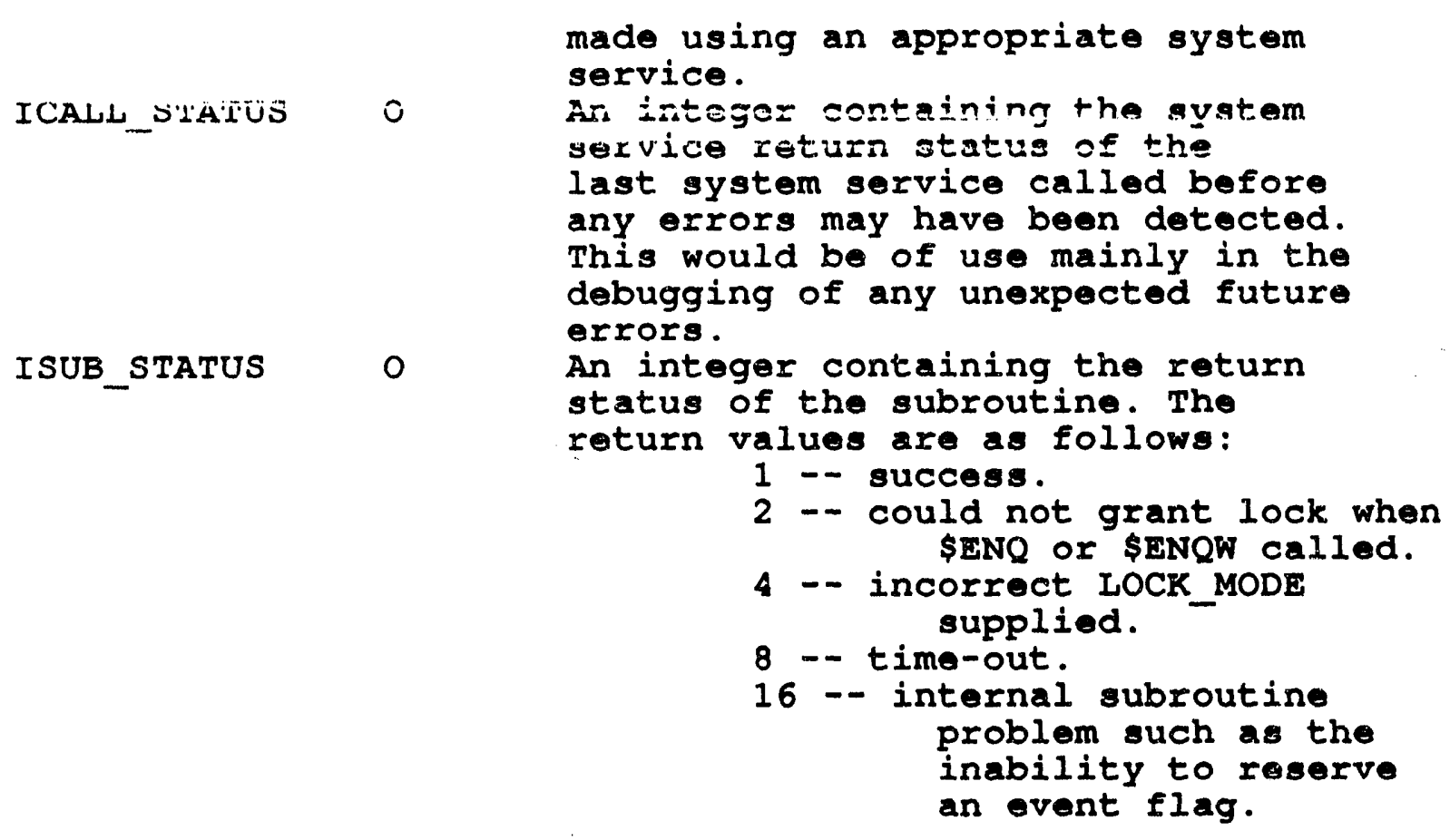

\section{INITIATION :}

Segments of a sample FORTRAN program calling this subroutine and companion subroutine UNLOCK are shown below:

PROGRAM SAMPLE

C...

C... Lock file WD:ARCDT1.DAT for purposes of reading using name

C... ATCDT as agreed upon by cooperating users. Allow 20.0

C... seconds to accomplish locking.

C...

CALI LOCK ('ARCDT','PR',20.0,LOCK_STATUS,LOCK_ID, ICALL_STATUS, 1 ISUB STATUS)

IF (ISUB STATUS) THEN

ELSE OPEN (UNIT=1, NAME =' WD : ARCDT1.DAT', . .

ENDIF GO TO (error handling routine)

c...

CLOSE (UNIT=1)

C... Release lock. 
C. . .

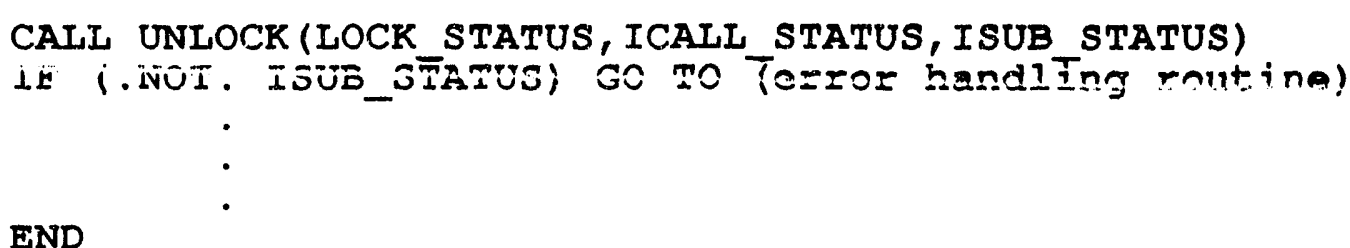

CAILING SEQUENCE:

This subroutine should be called prior to accessing a file (or other system resource) that is subject to being accessed by other programs in an incompatible way. The system services reference manual details the types of locks that can be placed on a resource to ensure that cooperating programs do not interfere with each other when accessing system resources. The two most common locks required are ' $\mathrm{xx}^{\prime}$ (exclusive) for writing into a file and 'PR' (protected read) for reading from a file. 'EX' grants exclusive access to a file and ' $P R^{\prime}$ only allows other readers into the file. When access to a resource is no longer required, companion subroutine UNLOCK should be called to release the resource.

INITIALIZATION: N/A

REAL TIME CONSIDERATIONS: N/A

AUTHOR: J.R. Froggatt, On-Line Systems Group, ESD, E.I. DuPont

DATE: $7 / 23 / 82$

LAST MODIFIED: 6/11/86 - eliminate lock value block handling by \$ENQ.

6.4 T_SWITCH_SET (Set T Switches To Allow Data Collection By Desired Computer)

IDENTIE ICATION :

Archiving system T-Switch set function

NAME : T_SWITCH_SET

TYPE: WIND System function

FUNCTION :

This routine switches the T-Switches directing data and terminal lines to either of the two WIND system VAX computers. If the argument SETTINGS supplied to this routine is equal to the string 'SWNORM' then the normal switch settings on T SWITCH_1 of $(0-7)$ going to $A$ (WIND2::) and $(8-15)$ going to $B$ (WIND1::) are made. 
Also, the normal switch settings on $T$ SWITCH 2 with all switches set to A (WIND2::) are made. If SETTINGS Is equaI to 'SWIND2' then all switches are set to $A$ on botir I swilches. If SrTmIx!s is emin? to 'SWIND2' all switches are set to $B$ on both $T$ switches.

AUTHOR: J.R. Froggatt, Process Computer Services Group, ESD, E. I. Dupont

DATE : $9 / 15 / 88$

6.5 TMPGET (Temporary Routine To Retrieve Current Met Data From WD:ARCCUR.DAT)

IDENT IE ICAT ION :

Temporary sub to read current 15 minute data record from WD: ARCCUR.DAT and place into local commons ARCOM, ARCOM_TP, and ARCOM_CL.

NAME : TMPGET

\subsection{UNLOCK (Release Resource Lock)}

NAME: SUBROUTINE UNLOCK

FUNCTION: Subroutine to release resource locks

TYPE: General subroutine

EUNCTION DESCRIPTION:

This subroutine Lleases a resource lock specified by the calling program thru the use of the lock manager system service \$DEQ. The calling program only needs to supply the LOCK STATUS Block, a 6 integer array created when subroutine Iock calls system service \$ENQ or \$ENQW to establish the lock. The subroutine returns the completion status supplied by $\$ D E Q$ indicating that it succeded or why it failed and a general subroutine status indicating success or failure of the subroutine. This variable will contain a 1 for successful completion and a 2 for unsuccessful completion.

ARGUMENTS :
NAME
$I / O$
DESCRIPTION

LOCK_STATUS I

A 6 integer array containing status information about the lock. It was returned by the LOCK subroutine when the 


$\begin{array}{ll}\text { ICALI_STATUS } & 0 \\ & \\ \text { ISUB_STATUS } & 0\end{array}$

lock was initially granted. It contains all the information lequirad $b_{y}$ sütam service DEQ to unlock the rescirse. $\star \star \star$ Currently the Lock Value Block (last four integers in the array) are not used by the LOCK subroutine and are set to 0 by it. $* \star \star$

An integer containing the return status of system service DEQ after it attempted to remove the lock. This would be of use mainly in the debugging of any unexpected future errors.

An integer containing the return status of the subroutine. The return values are as follows:

1 - - success

2 -- could not release lock when \$DEQ called

\section{INITIATION :}

Segments of a sample FORTRAN program calling companion subroutine LOCK and this subroutine are shown below:

PROGRAM SAMPLE

C...

C... Lock file WD:ARCDT1.DAT for purposes of reading using name

C... ARCDT as agreed upon by cooperating users. Allow 20.0

C... seconds to accomplish locking.

C...

CALL LOCK ('ARCDT','PR', 20.0, LOCK_STATUS, LOCK_ID, ICALL_STATUS, 1 ISUB STATUS)

IF (ISUB STATUS) THEN

ELSE

ENDIF OPEN (UNIT $=1, \mathrm{NAME}={ }^{\prime}$ WD : ARCDT $1 . D A T ', \ldots$

$$
\text { GO TO (error handling routine) }
$$

C...

CLOSE (UNIT $=1)$

C... Release lock.

C... 


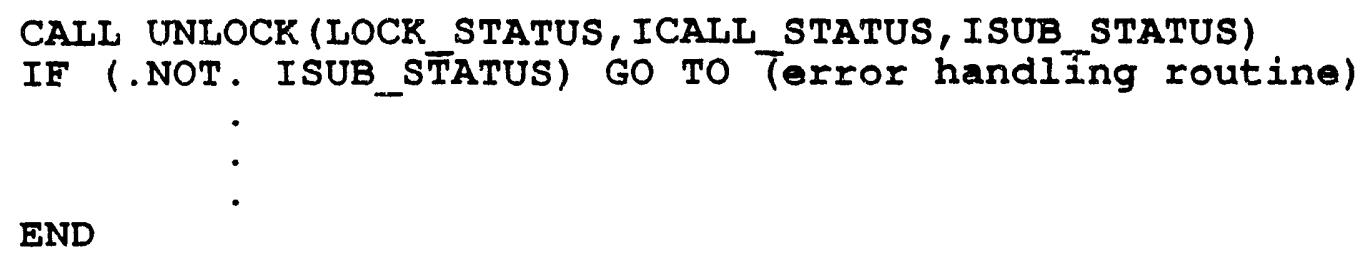


CHAPTER 7

* * DAI'A FIIES **

\subsection{WD:HRAIX1.DAT (Weekly SAM Average File)}

GENERAL DESCRIPTION:

File contains hourly SAM averages for a period of 1 week beginning at 23:30:00z Saturday and extending thru 23:29:59z the following Saturday. Each Hourly SAM average represents four 15 minute periods of the week and consists of the two 15 minute periods prior to the ropresented hour and the two 15 minute periods following the represented hour. Thus the range of hours represented by the above specified time span is from $00 \mathrm{z}$ Sunday to $23 \mathrm{z}$ the following saturday. The first record contains header record information and the remaining records contain TV and SRS Tower SAMs averaged over four 15 minute periods. Each data record contains data for a particular 1 hour period beginning with $00 \mathrm{z}$ sunday and extending thru $23 \mathrm{z}$ the following Saturday as indicated above. This file is used every other week. On alternate weeks WD: HRAIX2.DAT, an identically structured file, is used. A general subroutine HIXCLC is used to determine which of these two files and which record in the file corresponds to a particular time expressed as HH:MM:SS MM/DD/YY. Data from this file is used as input to program HRAVPT to generate hourly plume displays at 32 minutes after the hour. After the file is complete 23:29:59z Saturday, companion file WD: HRAIX2.DAT is started 23:30:00z the same day. The data will. remain in WD:HRAIX1.DAT until the following Thursday at which time ZEROAC will execute and zero out the file in preparation for the collection of new data beginning the following saturday. ZEROAC actually clears the file out Thursday, Friday, and Saturday redundantly in case of computer outage during one or two of the scheduled run times. Data must be transferred from the file to mag tape by Procedure SAMTAP for long term storage before the information is zeroed out on Thursday. Files WD: HRAIX1.DAT and WD:HRAIX2.DAT alternate back and forth on a weekly basis with 1st one collecting data and then the other. 
READ BY: HRAVPT, PLMDSP, ... AnY pgm using Subroutine HRAGET.

FIIE TYPE: Indexed/Unformatted

HEADER RCD CONTENT: HDRI: IEIRST, ILAST, ArYaY IHDARR(12), AXYaY RECFLG(11) $(I \star 2, I \star 2,12 I * 2,11 I * 2)$

IFIRST $=$ Index of 1 st record containing data

ILAST = Index of last record containing data

Array IHDARR as follows:

1) Month of first data reading

2) Day

3) Year

4) Hour

5) Min

6) Sec

7) Month of last data reading

8) Day

9) Year "

10) Hour

11) Min

12) Sec

Array RECFLG(11) as follows:

(Each successive bit corresponds to a record in the file)

Bit 0 RECFLG(1) = 1 if any data in file

$=0$ if no data in file

Bits 1-15 RECELG(1):

$=1$ if data in corresponding record

$=0$ if no data in corresponding record

Bits 0-15 RECELG (N) (for $\mathrm{N}=2-10$ ):

$=1$ if data in corresponding record

$=0$ if no data in corresponding record

Bits 0-9 RECELG (11):

$=1$ if data in corresponding record

$=0$ if no data in corresponding record

RECORD FORMAT: RECS 2-169: ITEST

$(I \star 2)$

IHR

$(I * 2)$

IMIN

ISEC

$(I * 2)$

IMO

$(I * 2)$

IDAY

IYR

$(I * 2)$

SEC

$(I * 2)$

DIREC

$(R * 4)$

SPEED

$(R \star 4)$

SIGAZ

$(R * 4)$

SIGEL

Significance of data as follows:

ITEST: = 0 If no data in record

$=1$ If data in record

IHR - IYR: Time Date of last data collected 
SEC: of seconds over which data collected

DIREC - SIGEL: SAM AVERAGE AZM, SPEED(M/S), SIGAZ, SIGEL OVER THIT GO MIINYUTE INTERYYAT.

NUMBER OF RECORDS : 169

SIZE IN BLOCKS: 14

\subsection{WD:HRAIX2.DAT (Alt Weekly SAM Average Eile)}

GENERAL DESCRIPTION:

Companion file to WD:HRAIX1.DAT. The description for that file applies to this file.

CREATED/URDATED BY: HRAV, HRAVNP, HRAVCR

READ BY: Same as WD:HRAIXI.DAT

EILE TYPE: Indexed/Unformatted

HEADER RCD FCRMAT: SAme as WD:HRAIX1.DAT

RECORD FORMAT: Same as WD:HRAIX1.DAT

NUMBER OF RECORDS : 169

SIZE IN BLOCKS: 14

\subsection{WD:ARCDT1.DAT (Weekly WIND Archive Data)}

GENERAL, DESCRIPTION :

File contains Arinive Data for a period of 1 week beginning at 00:00:00z Sunday and extending thru 23:59:59 saturday. The first record contains header record information and the remaining records contain TV, Plant, and Climatology tower data averaged over 15 minute periods. Each data record contains data for a particular 15 minute period beginning with 00:00:00 - 00:14:59 Sunday (the first day of the week) and extending thru 23:45:00 - 23:59:59 saturday. This file is used every other week. On alternate weeks WD:ARCDT2.DAT, an identically structured file, is used. A general subroutine INXCLC is used to determine which of these two files and which record in the file corresponds to a particular time expressed as HH:MM:SS MM/DD/YY. Data from this file is used as input to the Emergency Response Codes as well as to other displays and reports of weather conditions at the plant site. After the file is complete 23:59:59z saturday, companion file WD:ARCDT2.DAT is started 00:00:00z sunday. the data will remain in WD:ARCDT1.DAT until the following 
Thursday at which time ZEROAC will execute and zero out the file in preparation for the collection of now lata bsgixning the follnwing sunday. ZEROAC actually clears the lile out Thursday, Friday, and saturday redundantly in case of computer outage during one or two of the scheduled run times. nata must be transferred from the file to mag tape by pr jure ARCTAP for long term storage before the information is zeroed out on Thursday. Files WD:ARCDT1.DAT and WD:ARCDT2.DAT alternate back and forth on a weekly basis with lst one collecting data and then the other.

CREATED/UPDATED BY: ARCIV2

READ BY: HRAV, ARCDSP, ... AnY pgm using subroutine ARCGET.

FILE TYPE: Direct Access/Unformatted

HEADER RCD CONTENT: HDR1: ArraY IHDARR(14), ArraY RECELG(674)

(14 I*2, $674 I * 1)$

Array IHDARR as follows:

1) Number of first record containing data

2) Number of last record containing data

3) Month of first data reading

4) Day

5) Year

6) Hour

7) Min

8) Sec

9) Month of last data reading

10) Day

11) Year

12) Hour

13) Min

14) Sec

Array RECFLG as follows:

RECELG(1) = 1 If any data in file

$=0$ If no data in file

RECFLG (N) (FOR N $=2-673$ )

$=1$ If data in corresponding record

$=0$ If no data in corresponding record

RECORD FORMAT: RECS 2 - 673: ITEST

SECNDS

NOOBS

NOTVRD

NOSVRD

NOAPRD

ARRAY TDTBYT $(6,2)$

ARRAY TVBYT $(36,6)$

ARRAY TVINT (36)

ARRAY TVSP $(36,8)$

ARRAY SVBYT $(36,6)$

ARRAY SVINT (36)

ARRAY SVSP $(36,8)$

$(I \star 2)$

$(R \star 4)$

$(I * 2)$

$(I * 2)$

$(I * 2)$

$(I \star 2)$

(12 $B * 1$ )

(216 $B * 1$ )

(36I*2)

(288 R*4)

(216 $3 * 1$ )

(36 I×? )

(288R*4) 


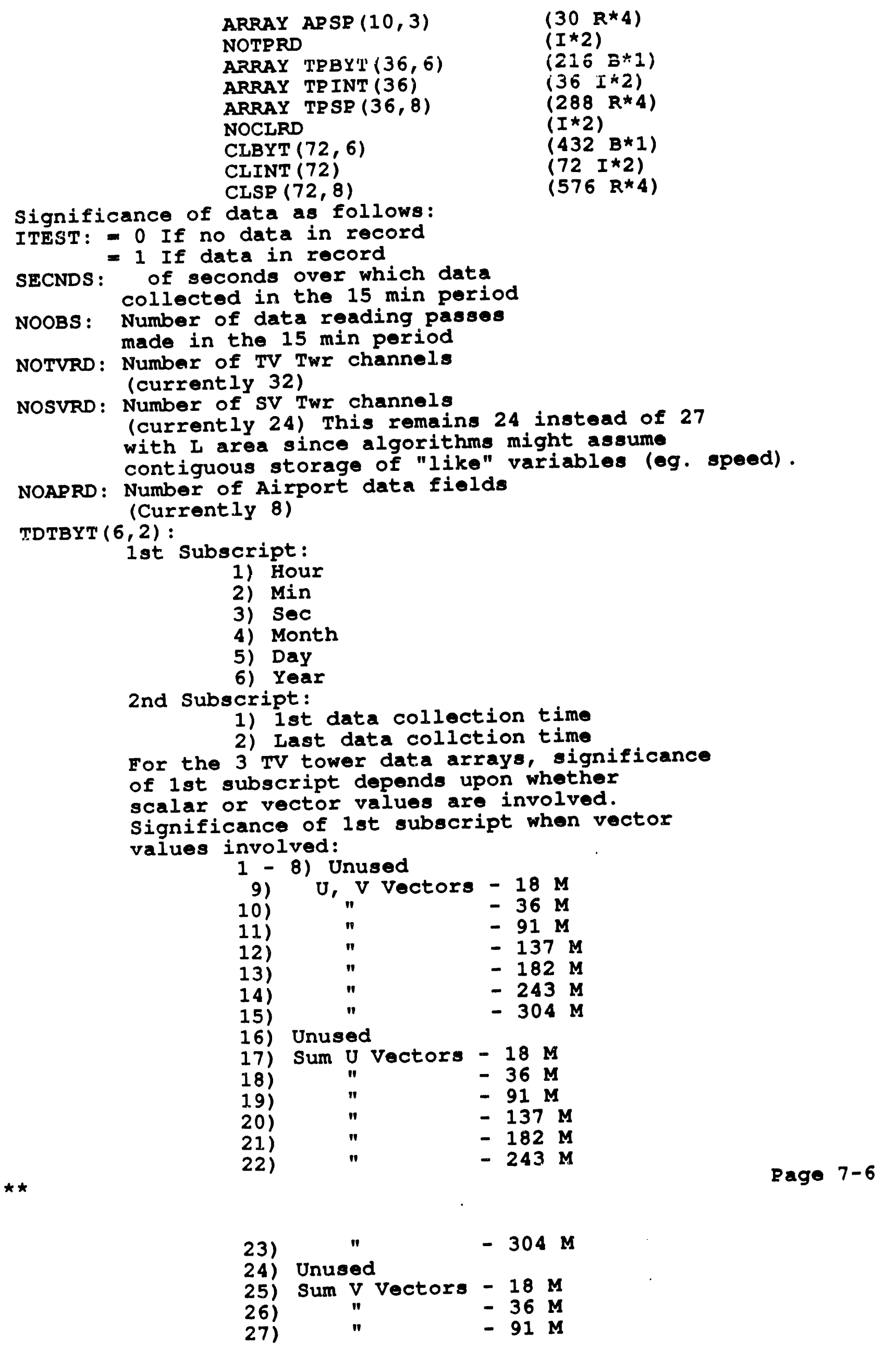




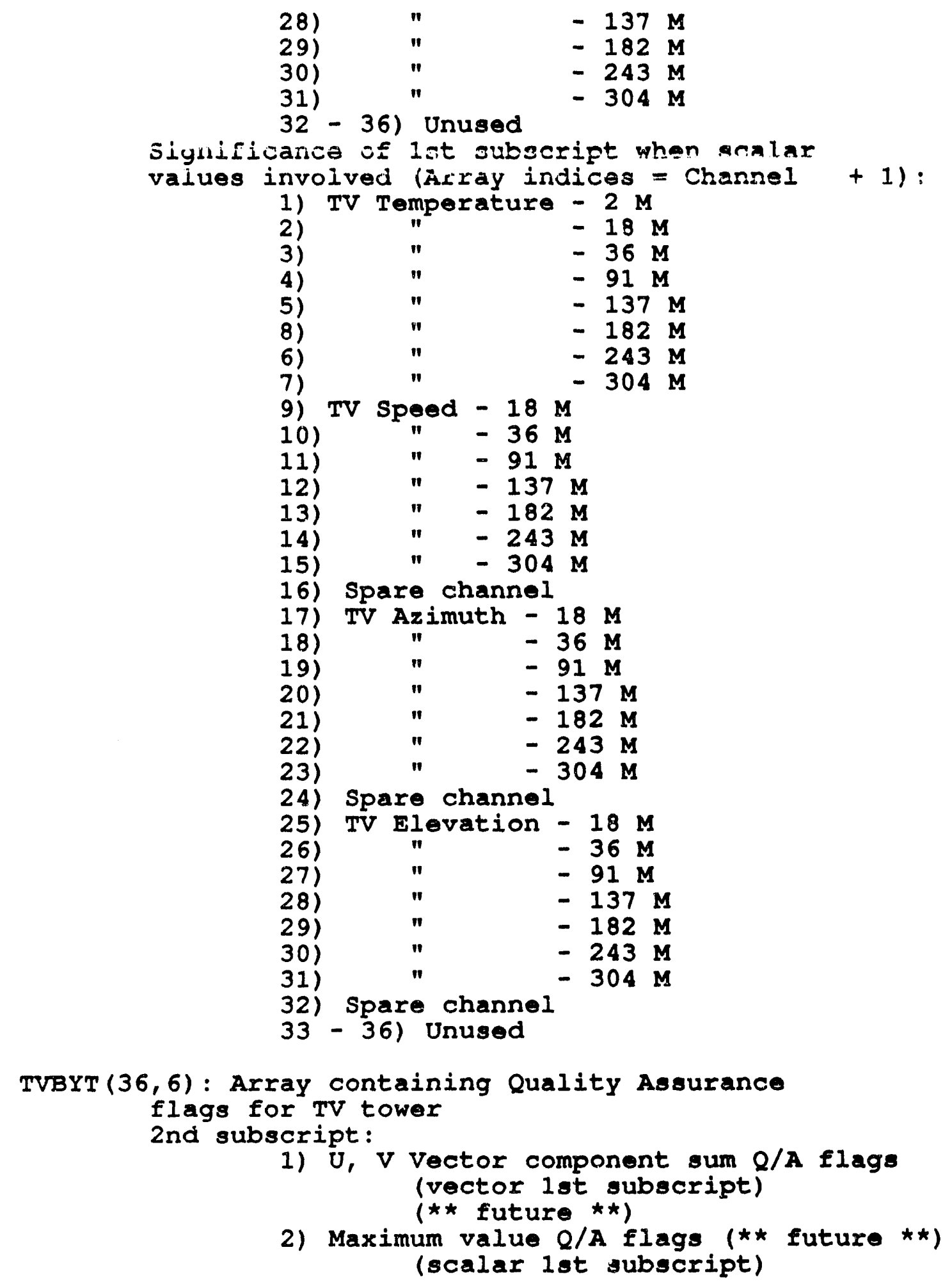




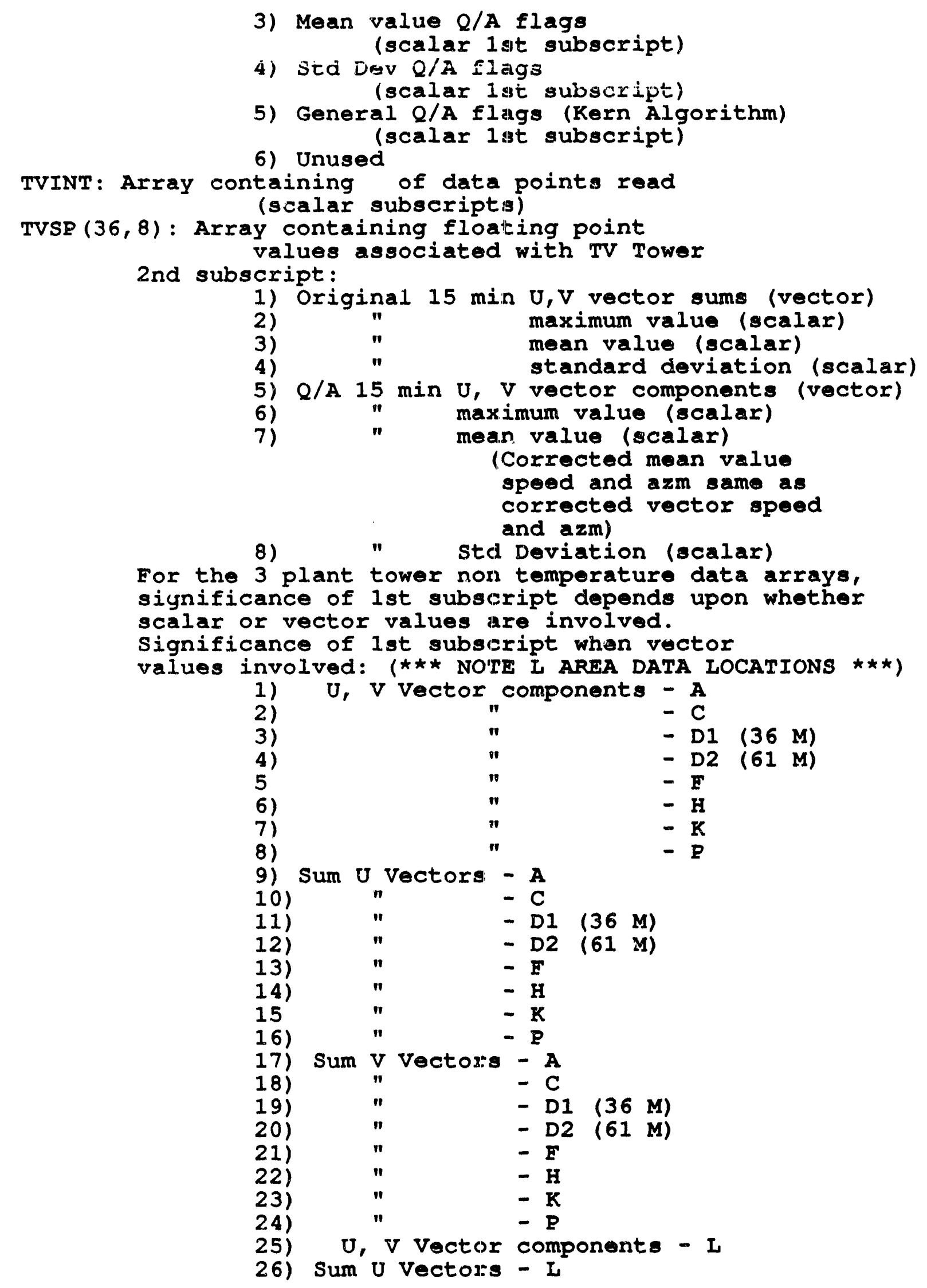




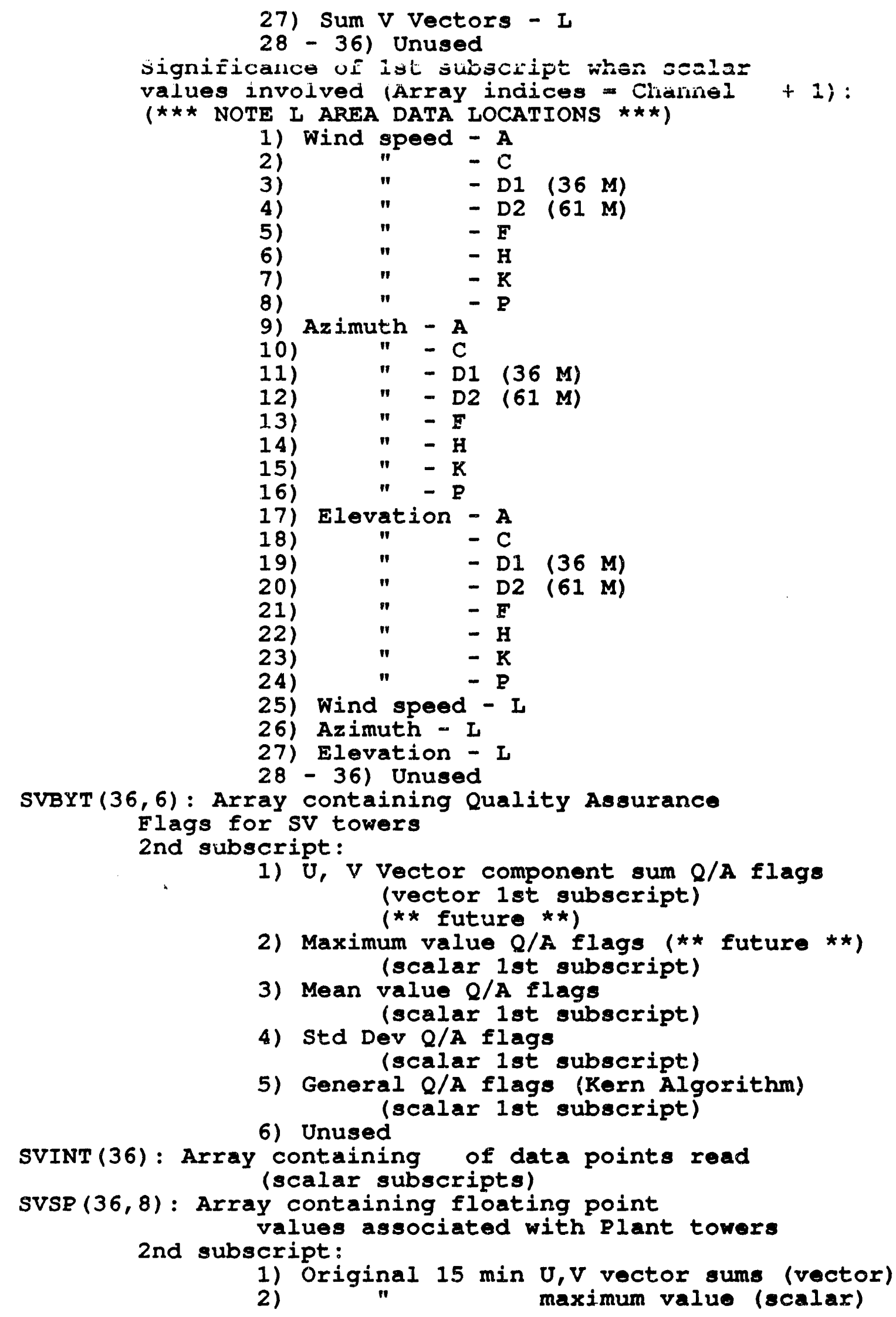




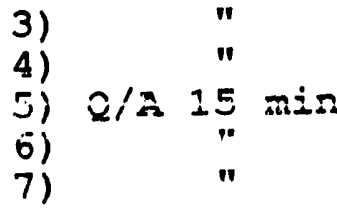

APSP $(10,3)$ : Array to contain up to 10 values

speed and azimuth)

for up to 3 Airports. Currently

6 values are being stored

for Bush Field.

$1,1)$ Bush Field

$2,1)$

$3,1)$

$4,1)$

$5,1)$

$6,1)$

$7,1)$

$8,1)$

$9,1-10,1$

$1,2-10,2)$

$1,3-10,3)$ direction

speed (knots)

temp (deg $F)$

dew pt temp (deg E)

stability

hour (zulu time)

sea level presaure

visibility

Bush Field spares

2 spares

3 spares

NOTPRD: Number of plant temperature channels

(currently 24). This remains 24 instead of 27

with $I$ area since algorithms might assume

contiguous storage of "like" variables (eg. dew point).

For the 3 plant tower temperature data arrays,

significance of lst subscript is as follows:

(Array indices = Channel +1 )

$(* \star \star$ NOTE I AREA DATA LOCATIONS $\star \star \star)$ )

1) Temperature (61M) - A

2)

3) Unused

4) Temperature (61M) - D

5) " - F

6) " - H

7) "

9) Dew Point (61M) - A

10) " - C

11) Unused

12) Dew Point (61M) - D

13) " - F

14) " $-\mathrm{H}$

15) " $-\mathrm{K}$

16) " - P

17) Temperature (2M) - A

18)

20) Temperature (2M)

21)

22)

23)

$\begin{array}{ll}" 1 & -\mathrm{E} \\ " & -\mathrm{H} \\ & -\mathrm{K}\end{array}$




$$
\begin{aligned}
& \text { 24) } \\
& \text { 25) Temperature }(61 M)-P \\
& 26) \text { Dew Eoint (61M) - - L } \\
& 27) \text { Temperature (2M) }-I \\
& 28-36) \text { Unused }
\end{aligned}
$$

TPBYT $(36,6)$ : Array containing Quality Assurance

Flags for plant temps

2nd subscript:

1) unused

2) Maximum value $Q / A$ flags ( $* \star$ future $* \star$ )

3) Mean value $Q / A$ flag 3 ( $* *$ future $* *$ )

4) Std Dev $Q / A$ flags ( $* \star$ future $\star \star$ )

5) General Q/A flags (Kern Algorithm)

6) Unused

TPINT (36) : Array containing of data points read TPSP $(36,8)$ : Array containing floating point

values associated with plant towers

2nd subscript:

1) Unused

2) Original $15 \mathrm{~min}$ maximum value

3) " mean value

4) " standard dev

5) Unused

6) Q/A 15 min maximum value (** future - curr. same as original values)

7) " mean value (curr. same as orig.)

NOCLRD: Number of CL Twr channels standard dev (curr. same as orig.) (currently 40)

For the 3 CL tower data arrays, significance

of lst subscript depends upon whether scalar or vector values are involved.

Significance of 1 st subscript when vector values involved:

1) Sum U Vectors - $2 \mathrm{M}$

2) " $-18 \mathrm{M}$

3) " $\quad-36 \mathrm{M}$

4) $\quad-61 \mathrm{M}$

5) Sum V Vectors - $2 M$

6) " $-18 \mathrm{M}$

7) $"-36 \mathrm{M}$

8) $"-61 \mathrm{M}$

9) \#U, V Vectors - $2 M$

10) "

11) " - $36 \mathrm{M}$

12) " - $61 \mathrm{M}$

13 - 72) Unused

Significance of 1 st subscript when scalar

values involved (Array indices = Channel + 1):

1) $\mathrm{CL} A z i m u t h-2 \mathrm{M}$

2) " - $18 \mathrm{M}$

3) $\quad-36 \mathrm{M}$

4) " $-61 \mathrm{M}$

5) CL Elevation - $2 \mathrm{M}$ 


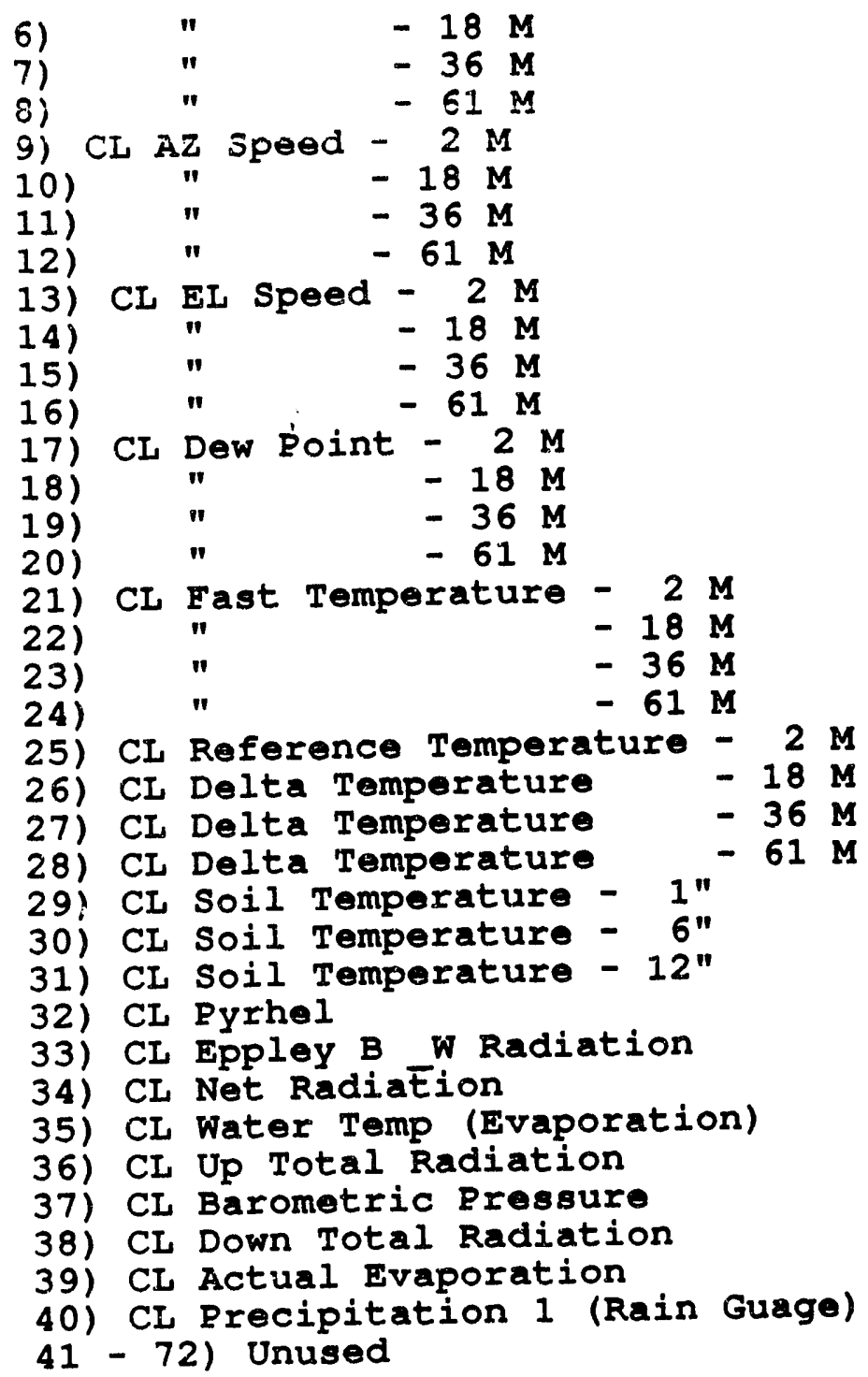

CLBYT $(72,6)$ : Array containing Quality Assurance flags for CL tower 2nd subscript:

1) U, V vector component sum Q/A flags (vector 1 st subscript)

$(* \star$ future $* \star)$ EXCEPTIONS: FOr first subscript: 37,39 , and 40 (scalar), the value contained is the first reading in the 15 minute period.

2) Maximum value $Q / A$ flags ( $* \star$ future $* \star$ ) (scalar 1st subscript) EXCEPTIONS: For first subscripts 37,39 , and 40 (scalar), the value contained is the last reading in the 15 minute period.

3) Mean value $Q / A$ flags ( $* \star$ future $* *$ ) (scalar lst subscript) 


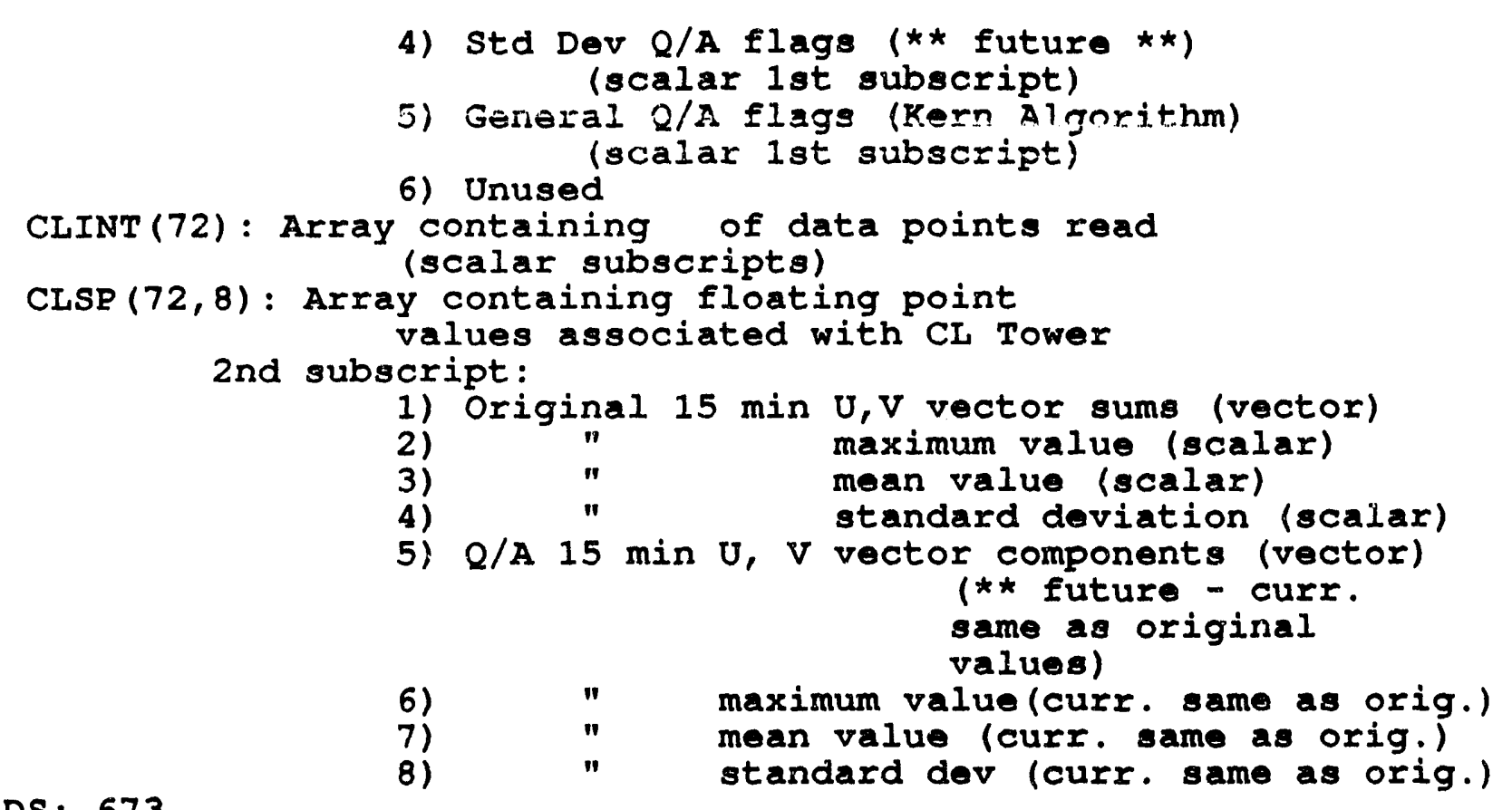

NUMBER OF RECORDS: 673

SIZE IN BLOCKS: 10095

7.4 WD:ARCDT2.DAT (Alternate Weekly WIND Archive Data)

GENERAI DESCRIPTION :

Companion file to WD:ARCDT1.DAT. The description

for that file applies to this file.

CREATED/UPDATED BY: ARCIV2

READ BY: Same as WD:ARCDT1.DAT

FIIE TYPE: Direct Access/Unformatted

HEADER RCD FORMAT: Same as WD:ARCDT1.DAT

RECORD FORMAT: Same as WD:ARCDT1.DAT

NUMBER OE RECORDS: 673

SIZE IN BLOCKS : 10095 


\subsection{WD:ARCDT3.DAT (WIND Archive Tape Restore File)}

GENERAL DESCKIETIOIN :

File is used to contain Archived Data restored from

tape covering a period of 1 week beginning at 00:00:00

Sunday and extending thru 23:59:00 Saturday. Data is inserted

into the file by Procedure ARCTAP. The data can then be accessed

in a manner similar to that used to retrive data from

either WD:ARCDT1.DAT or WD:ARCDT2.DAT.

CREATED/UPDATED BY: WC:ARCTAP.COM

READ BY: ARCDSP

FILE TYPE: Direct Access/Unformatted

HEADER RCD FORMAT: Same as WD:ARCDT1.DAT

RECORD FORMAT: Same as WD:ARCDT1.DAT

NUMBER C.E RECORDS: 673

SIZE IN BLOCKS: 10095 

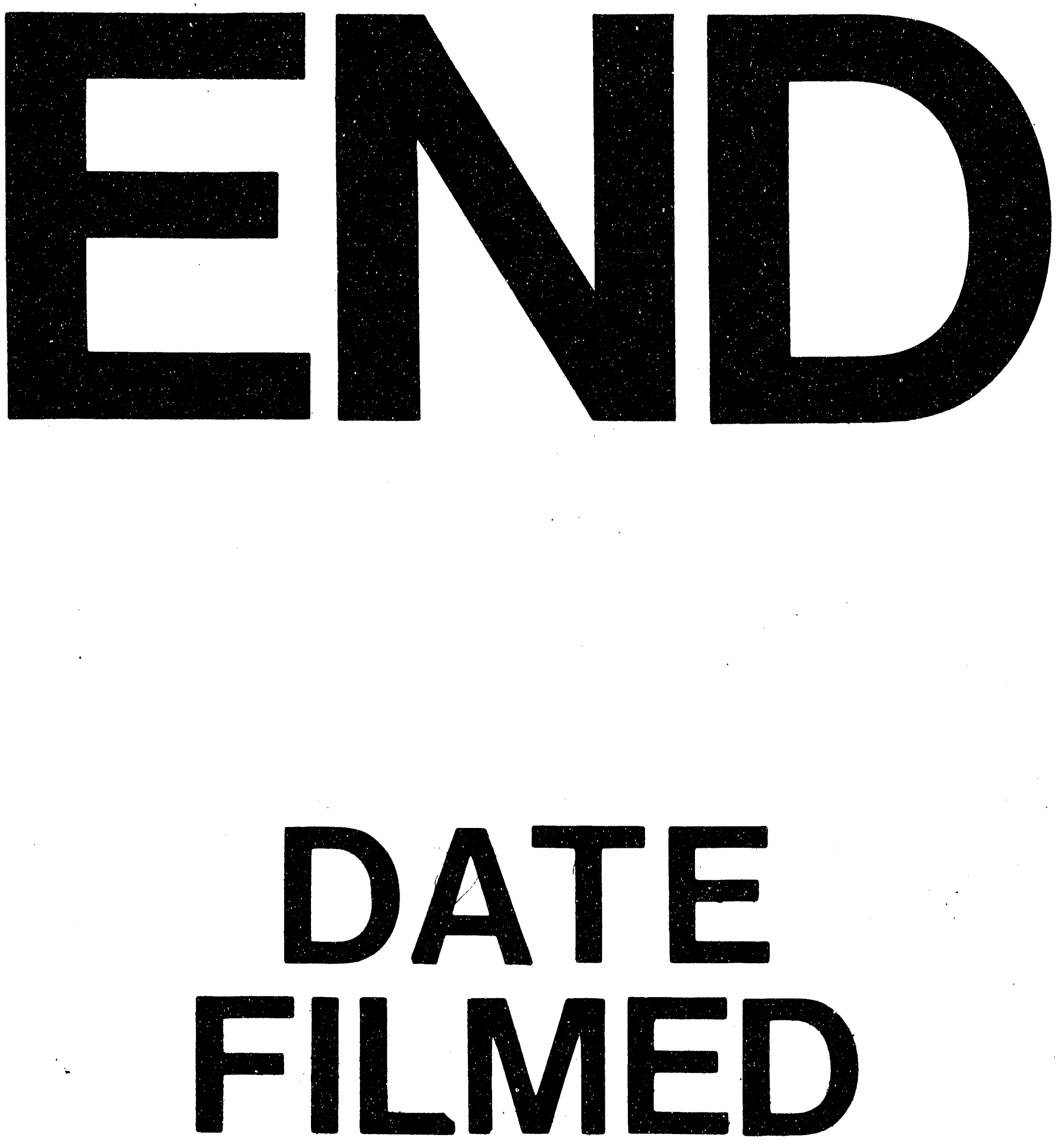

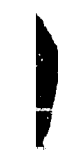

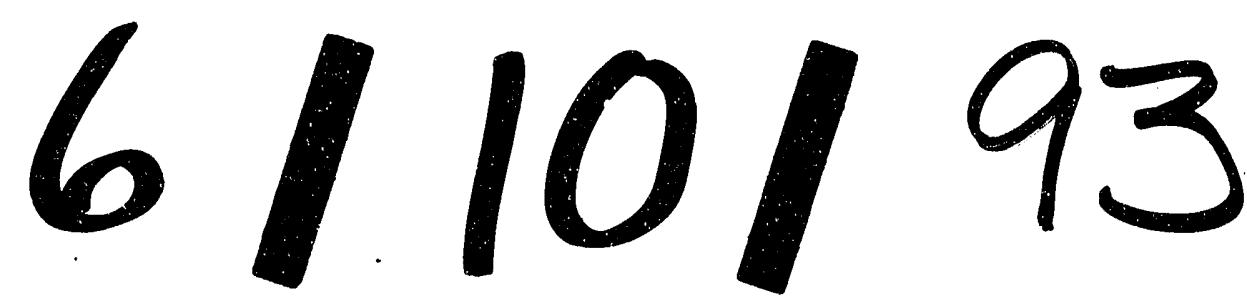


